IZA DP No. 4325

Monitoring Job Offer Decisions, Punishments, Exit to Work, and Job Quality

Gerard J. van den Berg

Johan Vikström

July 2009 


\title{
Monitoring Job Offer Decisions, Punishments, Exit to Work, and Job Quality
}

\author{
Gerard J. van den Berg \\ VU University Amsterdam, IFAU Uppsala, \\ CEPR, IFS and IZA \\ Johan Vikström \\ Uppsala University and IFAU Uppsala
}

Discussion Paper No. 4325

July 2009

IZA

P.O. Box 7240

53072 Bonn

Germany

Phone: +49-228-3894-0

Fax: +49-228-3894-180

E-mail: iza@iza.org

\begin{abstract}
Any opinions expressed here are those of the author(s) and not those of IZA. Research published in this series may include views on policy, but the institute itself takes no institutional policy positions.

The Institute for the Study of Labor (IZA) in Bonn is a local and virtual international research center and a place of communication between science, politics and business. IZA is an independent nonprofit organization supported by Deutsche Post Foundation. The center is associated with the University of Bonn and offers a stimulating research environment through its international network, workshops and conferences, data service, project support, research visits and doctoral program. IZA engages in (i) original and internationally competitive research in all fields of labor economics, (ii) development of policy concepts, and (iii) dissemination of research results and concepts to the interested public.
\end{abstract}

IZA Discussion Papers often represent preliminary work and are circulated to encourage discussion. Citation of such a paper should account for its provisional character. A revised version may be available directly from the author. 


\title{
ABSTRACT
}

\section{Monitoring Job Offer Decisions, Punishments, Exit to Work, and Job Quality*}

\begin{abstract}
Unemployment insurance systems include monitoring of unemployed workers and punitive sanctions if job search requirements are violated. We analyze the effect of sanctions on the ensuing job quality, notably on wage rates and hours worked, and we examine how often a sanction leads to a lower occupational level. The data cover the Swedish population over 1999-2004. We estimate duration models dealing with selection on unobservables. We use weighted exogenous sampling maximum likelihood to deal with the fact the data register is large whereas observed punishments are rare. We also develop a theoretical job search model with monitoring of job offer rejection vis-a-vis monitoring of job search effort. The observation window includes a policy change in which the punishment severity was reduced. We find that the hourly wage and the number of hours are on average lower after a sanction, and that individuals move more often to a lower occupational level, incurring human capital losses. Monitoring offer rejections is less effective than monitoring search effort.
\end{abstract}

JEL Classification: J64, C41, C21, J31, J44, J65, J62

Keywords: unemployment, duration, sanction, wage, hours worked, weighted exogenous sampling maximum likelihood, case worker, job offer, offer rejection, search effort

Corresponding author:

Gerard J. van den Berg

Dept of Economics

VU Univ Amsterdam

De Boelelaan 1105

1081 HV Amsterdam

The Netherlands

E-mail: gjvdberg@xs4all.nl

\footnotetext{
* We are grateful for helpful suggestions from Peter Fredriksson, John Ham, Bertil Holmlund, Per Johansson, Katarina Richardson, and participants in seminars at IFAU Uppsala and the University of Southern California and a workshop in Uppsala. Anna Nilsson provided excellent help with the institutional background. Part of this project was carried out while Vikström was at VU University Amsterdam as postdoc in the EU RTN "Microdata" network. We thank Susanne Ackum and the Swedish Ministry of Social Affairs, in particular Mats Wadman, for their encouragement and support for this project.
} 


\section{Introduction}

Unemployment Insurance (UI) systems typically include monitoring of unemployed workers and punitive sanctions for those who do not comply with job search requirements (see e.g. OECD, 2000, for an overview). Van den Berg, Van der Klaauw and Van Ours (2004) is the first published study of the causal effect of a punitive sanction on the transition rate from unemployment to employment. Since then, a range of similar studies has been carried out for different countries and time periods. See Van den Berg and Van der Klaauw (2005, 2006), for overviews. These studies do not consider the effect of a sanction on the type of job accepted. From a welfare point of view as well from the point of view of the unemployed individual, such effects are important. If the job accepted after a sanction is similar to the job accepted in the counterfactual situation of no sanction, then severe sanctions and intensive monitoring have less adverse longrun effects than if the former job is often worse than the latter. This relates to the more general issue of how steeply benefits should decline as a function of the elapsed unemployment duration, to balance moral hazard with the likelihood that unemployed individuals are driven into sub-optimal job matches (see e.g. Acemoglu and Shimer, 2000).

In this paper we address the effects of sanctions on the quality of the job that is accepted. We distinguish between effects on the wage and on working hours (specifically, full-time versus part-time). Wages and hours are potentially relevant margins along which unemployed individuals make job acceptance decisions. We use register data covering the full Swedish population over 1999-2004. This includes several hundreds of thousands of unemployment spells. The register data also include information on a large range of background characteristics of the individual, his/her household, and his/her local labor market conditions. If a spell is observed to end in a transition to work then in many cases we observe the above-mentioned job characteristics. Notice that observation of a wage rate is very unusual in register data on employment or, indeed, in annual longitudinal panel survey data. Such data typically only record annual income or annual earnings, which are composite measures based on both wages and hours worked. Our data enable us to distinguish between effects on wages and effects on hours.

One may argue that any effects on characteristics of the first accepted job after unemployment may fade away swiftly as individuals have the opportunity to search on the job and make transitions to jobs with better characteristics. We investigate this by examining the job conditions that prevail several years after the sanction. Moreover, we examine whether individuals make job acceptance 
decisions after a sanction that are more or less irreversible. Specifically, we observe the occupation of the accepted job, and we observe to what extent this differs from the occupation of the pre-unemployment job. On average, acceptance of a job with a lower occupational level involves a larger loss of human capital than acceptance of a job in the same occupation. This loss becomes irreversible as human capital depreciates over time. It may therefore be more difficult for the individual to move out of a bad job match if the job has a lower occupational level. This makes it important to know whether sanctions often lead to a match in a lower occupational level. By measuring the required number of years of education for each occupation, we can quantify the human capital loss due to the occupational downgrading caused by a sanction. Because of the existence of separate educational tracks, this is likely to be a lower bound of the true loss.

The empirical analyses are based on the "timing of events" approach (see e.g. Abbring and Van den Berg, 2003). This involves the estimation of duration models for the duration to job exit and the duration until treatment (i.e., a sanction), exploiting random variation in the timing of the treatment and taking into account that treatment assignment may be selective in that the durations may be affected by related unobserved determinants. This is the standard approach in the literature on sanction effects. Indeed, one may claim that punitive treatments provide a best case application for this approach. This is, first of all, because the moment at which an individual is caught is by definition unanticipated by the individual, so that the "no anticipation" assumption on the joint distribution of counterfactuals is satisfied. Accordingly, the time until treatment. is to some extent driven by an element that is random from the individual's point of view. Secondly, unconfoundedness assumptions are almost by definition likely to be invalid, because individuals can only logically display inadmissible behavior if this behavior or its determinants are not fully observable in standard registers. To address effects of dynamically assigned treatments on post-duration outcomes, like post-unemployment wages, it becomes a necessity to deal with dynamic selection due to unobserved heterogeneity even if the assignment process is randomized (see Ham and LaLonde, 1996, and Abbring and Van den Berg, 2005).

In addition to the analysis of sanction effects on job characteristics, our paper makes three other major contributions to the literature (for convenience, we refer to these as contributions 2, 3 and 4). To understand the importance of two of these, we should start by pointing out two special features of the Swedish UI monitoring system. First, the monitoring of an unemployed individual is carried out by the same case worker who also provides job search assistance to the individual. This case worker is the only person who can take the initiative to give a 
sanction. This is a marked difference with monitoring in other countries, which is typically carried out by agencies that are distinct from the agencies providing job search assistance to the unemployed. Secondly, after inflow into UI, monitoring focuses on job offer decisions, in the sense that unemployed individuals are not supposed to reject suitable job offers. This is also in contrast to monitoring in other countries, which typically focuses on search effort, as measured by the number of applications sent out or indicators of the willingness to adhere to job search guidelines.

The second major contribution of the paper is that we study a policy change in the monitoring system during the period under observation. Before February 5 , 2001, the only possible punishment rate was a rate of $100 \%$ (i.e., complete UI benefits withdrawal) for a certain amount of time. After that, the default rate was $25 \%$. The underlying motivation for this change was that the personal connection between the case worker and the person he/she was supposed to help made it difficult for the former to propose a punishment that amounted to the full withdrawal of the latter's income. It was felt that more modest sanctions would increase the threat effect of sanctions and thereby would increase the exit rate to work for those not (yet) punished. The decision to change the punishment rate was made and announced only shortly before the implementation date. In theory, this provides a "regression discontinuity" that the analyst may use to identify the threat effect of a monitoring system. With our population-level data, we aim to pursue this. We examine changes in sanction rates and the exit rate out of unemployment before and after the policy change.

The estimation results and differences with estimates in the literature can be understood by resorting to a job search theoretical model framework. The third major contribution of the paper is that we develop and analyze a theoretical model with monitoring of job offer decisions in the presence of wage variation. The theoretical predictions can be contrasted to those from a model with monitoring of job search effort or search intensity. We find some qualitative differences, and these by itself contribute to our understanding of efficient policy. Notice that monitoring of offer decisions increases the relevance of studying effects on job quality, because rejected offers typically concern jobs with a low job quality.

The fourth major contribution is methodological. "Timing of events" models are usually estimated with random samples from the inflow into the state of interest, by maximum likelihood. However, in the case of a rare treatment, the random sample needs to include many individuals in order to obtain a sufficient number of individuals who are observed to be treated. Estimation with very large samples is computationally demanding. We therefore propose to esti- 
mate the models with endogenously stratified samples, using weighted exogenous sampling maximum likelihood (WESML). Accordingly, the sample we use contains all individuals observed to get a sanction, plus a subsample of the other individuals. This estimation method has not yet been used in the context of bivariate dependent-duration models (see Ridder, 1986, and Amemiya and Yu, 2006, for applications to univariate duration analyses with endogenously stratified samples). The method requires certain aggregate population statistics, but recall that we observe the complete population of Sweden.

The main empirical result of the paper is that, on average, sanctions cause individuals to accept jobs with a lower hourly wage and less working hours per week. The estimated average reduction in the accepted wage is almost $4 \%$. In addition, sanctions causally increase the likelihood of the acceptance of a job at a lower occupational level, incurring a permanent human capital loss that is on average equivalent to at least some weeks of formal education. The theoretical analysis suggests that these adverse effects can be partly (but not fully) prevented if the system of job-offer-decision monitoring is replaced by a system of search-effort monitoring. The combination of the theoretical analysis and the data analysis suggest that the current Swedish system does not exert substantial "ex ante" or threat effects of monitoring on the job exit rate of not-yet punished unemployed individuals. It is plausible that a system of search-effort monitoring that is not carried out by the case worker who provides job search assistance would actually create a larger threat effect. Methodologically, our paper suggests that WESML with an endogenously stratified sample containing all treated is a very useful method for the estimation of causal effects of rare endogenous events on duration outcomes, if one has access to a large data set and population statistics. In particular, it is very useful for the estimation of dynamically assigned treatments on duration outcomes if treatments are rare and one has population-level register data.

The outline of the paper is as follows. Section 2 presents the institutional setting. It discusses the Swedish UI system and the role of monitoring and sanctions in that system. It also describes the monitoring policy reforms in our observation window. Section 3 provides the theoretical job search framework and derives theoretical predictions. Section 4 gives a detailed description of the data. In Section 5 we discuss the empirical approach and the WESML estimation method. Section 6 presents the empirical results. Section 7 concludes. 


\section{Unemployment insurance}

\subsection{Unemployment insurance entitlement}

This subsection describes the relevant features of the UI system on January 1, 2001. In Subsections 2.2 and 2.3 we discuss the monitoring system and the corresponding policy change in 2001. For a detailed description of other UI reforms during our observation window see Olli Segendorf (2003) and Bennmarker, Carling and Holmlund (2007). These are mostly reforms in local features of the function from the labor market history to the UI level.

An unemployed (part-time or full-time) individual in Sweden is entitled to UI benefits if a range of conditions are fulfilled. First, the individual must have been member of an unemployment insurance fund for at least 12 months and should have had a job for at least six months in the past 12 months. Secondly, he needs to be registered at the public employment service (PES) and has to be able and willing to work at least three hours a day and at least 17 hours per week. Further, he must state that he is actively searching for employment.

Those who fulfill these conditions are entitled to wage-related UI benefits. These amount to $80 \%$ of the average earnings during the latest six months of employment, with a floor and a ceiling. In the beginning of 2001 these were SEK $270(\approx € 25)$ and SEK 580 a day $(\approx € 55)$ per day. Individuals who have not been a member of an UI fund for at least 12 months may qualify for the Unemployment Assistance (UA) system. Compensation in UA is unrelated to previous earnings and the generosity of UA is much lower than UI. In our analysis we restrict attention to UI recipients. To retain UI during a spell of unemployment, the individual needs to remain eligible.

In 2001, the entitlement duration of UI benefits was 300 days for everyone. The benefits could either be collected continuously or with breaks in between the collection periods. If the individual finds a job and retains it for six months then he qualifies for new entitlement period. The individual also continues to collect UI benefits while being enrolled in a specific labor market program (the activity guarantee). ${ }^{1}$ UI benefits are mainly financed by proportional pay-roll taxes.

\footnotetext{
${ }^{1}$ Case workers assess the need for program participation if individuals are close to the end of their entitlement period. If such need is found then the individual is assigned to the "activity guarantee" which includes different monitoring activities.
} 


\section{$2.2 \quad$ Monitoring and sanctions}

The monitoring of an unemployed individual is carried out by the case worker of the PES office. This is the same person as the case worker who provides job search assistance to the individual. The case worker's identity usually does not change during the unemployment spell.

The case worker is supposed to examine whether the individual's job search behavior is in accordance to the UI guidelines. This concerns the verification that the individual has not rejected suitable job offers. The case worker is the only person who can take the initiative to give a sanction. A sanction is a benefits reduction for a limited time as a punishment for violation of the guidelines. ${ }^{2}$ The case worker is also supposed to verify during the course of an unemployment spell that the unemployed individual does not violate the UI entitlement conditions in the first place. This concerns, for example, unreported employment. If the individual is deemed non-eligible then he is not registered anymore as being unemployed. Moreover, his UI benefits payment is terminated immediately and for an indefinite period of time. ${ }^{3}$

The assignment of a sanction involves a number of stages. First, the case worker at the PES office observes an infringement. The employment office then prepares a report to the unemployment insurance fund, stating the infringement but not yet the sort of sanction it thinks is suitable. The unemployed individual is informed about the report and is given the opportunity to comment on his behavior. In practice, case workers may contact the unemployed individual before preparing the report, to prevent that the apparent infringement was due to a misunderstanding. A copy of the report is sent to the central public unemployment office (AMS). ${ }^{4}$ In the third stage, a decision about the sanction is made by the unemployment insurance fund, and a motivation is provided. In $86 \%$, the PES report results in approval of a sanction by the board; see IAF (2007). In a fourth stage, there may be an appeal to revert the decision. About $10 \%$ of all decisions

\footnotetext{
${ }^{2}$ In addition to this, UI benefits can be reduced if the individual has left employment without a valid reason or due to improper behavior at the work floor. UI is then suspended for a maximum of 45 days. We do not analyze this type of temporary benefits reduction because our data do not allow for a distinction between causal effects and selection effects of treatments that start at the beginning of a spell.

${ }^{3}$ In addition, eligibility is terminated if the individual sabotages cooperation with the employment office, for example by refusing participate in an individualized "action plan" which is a pathway back to work with possibly active labor market program participation. In accordance with the definition of unemployment, we regard such eligibility losses as exits from the state of unemployment.

${ }^{4}$ Nowadays, the inspection of the unemployment insurance (IAF) rather than AMS receives a copy.
} 
are asked to be reverted, but in only about $20 \%$ of these is the decision partly or fully reversed. Subsequently, one may appeal against a sanction at the county administrative court (Länsrätten).

There are several unpredictable events in this process. The case workers do not always observe that an unemployed has turned down a job offer. Whether a report is written or not depends on the attitude of the case worker (Swedish overviews, like IAF, 2006, state that case workers report themselves that there are differences in interpretation of the regulations between counties and employment offices and between individual case workers working at the same employment office). The benefit sanction decision may also depend on the board members attending the UI fund meeting. All this makes it unlikely that UI claimants anticipate the imposition of the sanction with great accuracy.

Before the reform of February 5, 2001, the only available sanction was a $100 \%$ reduction of the benefits level for a period of 10 to 60 days. The choice of the length of the sanction period was supposed to take the (subjectively assessed) expected remaining duration of unemployment into account. In practice, however, only a period of 60 days was used.

As noted in Section 1, the Swedish monitoring system was (and is) notably different from the systems in many other countries (see Grubb, 2000, for details about the systems in other countries). First, monitoring and job search assistance are carried out by the same case worker. In other countries, monitoring is typically carried out by agencies that are distinct from the agencies providing job search assistance. Secondly, after inflow into UI, monitoring mainly restricts attention to job offer rejections. Other countries focus primarily on search effort, as captured by the number of applications sent out or indicators of the willingness to adhere to job search guidelines.

Accordingly, Sweden is an outlier in aggregate statistics of sanctions. First, the number of sanctions issued is very low. Figure 1 displays this number per month, between January 1999 and November 2004. In 2000, about 3000 sanctions were issued, on an average stock of 210,000 full-time unemployed UI recipients. In Gray (2003)'s ranking of countries by sanction occurrence (which, roughly speaking, is defined as number of sanctions divided by the number of unemployed), Sweden is the lowest among the nine European countries considered (Sweden 0.79, Germany 1.14, Belgium 4.2, Denmark 4.3, Finland 10.2, United Kingdom 10.3, Norway 10.8, Czech Republic 14.7, Switzerland 40.3). Figures in other OECD countries are typically much higher than the Swedish figure as well. Abbring, Van den Berg and Van Ours (2005) report that around 3\% of the inflow of UI recipients receive a sanction during the UI spell, in The Netherlands in 1993. Contrary to Sweden, 
a number of these countries, including Germany, The Netherlands, and Denmark, has witnessed strong increases in the occurrence of sanctions since the early 2000s (see e.g. Svarer, 2007, and Schneider, 2008). We shall argue below that the low Swedish sanction occurrence can be explained by institutional differences in the monitoring system.

\subsection{Policy change of the monitoring regime}

The uniquely low occurrence of sanctions in Sweden can be explained by a low effective level of monitoring. In the late 1990s it was felt that the magnitude of the punishment (100\% UI benefits reductions for 60 days) was too large in the eyes of the case workers. After all, the case worker is primarily trying to help the unemployed individual, and the former would find it morally difficult to punish the latter harshly. This could prevent case workers from reporting violations. At the time, many other countries have policies where sanctions are smaller than $100 \%$ of the UI level. Accordingly, the Swedish government changed the policy design on February 5, 2001 (see e.g. Government of Sweden, 2000, for a substantiation of the above-given description of the motivation for the policy reform). From that day onwards, UI is reduced by $25 \%$ for 40 days for firsttime offenders, and by $50 \%$ for 40 days second-time offenders. A third violation during the same UI entitlement period entails a full loss of benefits until new employment has been found. The decision to change the monitoring policy was made on December 21, 2000, which is 1.5 month before enforcement. The public employment office AMS arranged regional meetings to inform the case workers about the policy change. These were held between the middle of February, 2001, and April, 2001. Case workers complained that after these meetings certain details of the new policy regime were still not clear to them (personal communications).

Despite the policy change, the occurrence of sanctions has remained very low by international standards. In Subsection 4.3 we examine whether the occurrence of sanctions in our individual data registers displays differences before and after the implementation date. 


\section{Theoretical insights}

\subsection{A job search model with monitoring of job offer deci- sions}

In this subsection we present a job search model with monitoring of job offer decisions. This model takes distinguishing features of the Swedish UI monitoring system into account and has not been analyzed in the literature. It is a model of optimal behavior of unemployed individuals given the presence of a particular system in which sanctions can be imposed. The model helps to understand the effects of such a system on individual behavior. It also provides insights into the determinants of the rates at which jobs are found and sanctions are imposed and the relationships between these rates.

Our point of departure is a basic job search model with a fixed individual search intensity. Consider an unemployed individual who searches sequentially for a job. Job offers arrive according to the rate $\lambda$. Jobs are heterogeneous in their characteristics. For expositional convenience we take the wage as the only possible job characteristic in this subsection. Offers are random drawings from a wage offer distribution $F(w)$. Every time an offer arrives the decision has to be made whether to accept it or to reject it and search further. Once a job is accepted it will be held forever at the same wage. During unemployment, a flow of benefits $b$ is received, possibly including a non-pecuniary utility of being unemployed. The individual aims at maximization of the expected present value of income over an infinite horizon.

It is well known that in this model, under some regularity conditions, the optimal strategy of unemployed individuals can be characterized by a reservation wage $\phi$, giving the minimal acceptable wage offer. The transition rate to work equals $\lambda(1-F(\phi))$.

Now let us introduce monitoring in this model framework. We assume that the case worker samples a fraction $p$ of rejected job offers, and that on average a fraction $q$ of these rejected offers are deemed to be sufficiently suitable for the unemployed worker. Then a fraction $p q$ of the rejected offers should not have been rejected. Accordingly, the sanction rate equals $\lambda F(\phi) p q$. If $p=1$ then all offers are monitored, and if $p=q=1$ then each rejected offer entails a sanction. For a given $p$ and $q$, we assume that the individual does not know which rejected offers are sampled or which are deemed acceptable by the case worker, but that he does know the values of $p$ and $q$.

Some individuals will be more willing to take the risk of being given a sanc- 
tion than others, e.g. because they have a higher non-pecuniary utility of being unemployed. Obviously, if $p=q=1$ and the punishment is sufficiently severe in comparison to a job with the lowest possible wage, then all job offers are always accepted, and sanctions would never be given. To proceed, we need to be specific about what occurs after the imposition of a sanction. First of all, benefits (b) are reduced substantially. Secondly, $p$ is likely to increase. If the individual again violates the rules concerning job offer decisions, and this is observed by the case worker, then additional benefits reductions are imposed. We assume that the punishment for additional violations is so severe that the individual will avoid this at all cost, so we assume that all offers are accepted after imposition of a sanction. This implies that sanctions are imposed at most once in a given spell of unemployment. (A strategy in which individuals take a job upon imposition of a sanction, and quit immediately in order to make a "fresh start" in UI, would not be optimal: UI would be reduced again immediately after quitting because of "insufficient effort to prevent job loss"; see Section 2.)

For simplicity, we assume that the parameters $b_{1}$ (being the benefits level before a sanction is imposed), $F, \lambda, p, q$ and the discount rate $\rho$ are constant as a function of unemployment duration. Upon imposition of a sanction, $b$ is permanently reduced from $b_{1}$ to $b_{2}$, with $b_{2}$ constant as a function of unemployment duration. As a consequence, both within the time interval before a sanction and within the time interval after a sanction, the optimal strategy is constant over time.

Let $R_{1}$ and $R_{2}$ denote the expected present value of income before and after imposition of a sanction, respectively, and let $\phi_{1}$ denote the reservation wage before the sanction. We obtain

$$
\begin{aligned}
& \rho R_{1}=b_{1}+\lambda \mathbb{E}_{F}\left[\max \left\{\frac{w}{\rho},(1-p q) R_{1}+p q R_{2}\right\}-R_{1}\right] \\
& \rho R_{2}=b_{2}+\lambda \mathbb{E}_{F}\left[\frac{w}{\rho}-R_{2}\right] \\
& \text { with } \phi_{1}=(1-p q) \rho R_{1}+p q \rho R_{2}
\end{aligned}
$$

Equation (1) can be understood by interpreting $R_{1}$ as an asset for which the return flow equals the flow of what one expects to gain from holding the asset. The latter consists of two parts: $(i)$ the flow of benefits, $(i i)$ the job offer arrival rate times the expected gain of finding an acceptable job over staying unemployed. The second part is the mean over $F$ of the gain corresponding to a wage offer $w$. 
If one accepts $w$ then the associated present value is $w / \rho$, so the gain is $w / \rho-R_{1}$. If one rejects it then there is a probability $p q$ that one is caught, in which case the associated present value is $R_{2}$, and a probability $1-p q$ that one is not caught, with present value $R_{1}$. The gain is again equal to the new present value minus $R_{1}$. The derivation of (2) is analogous. Equations (1) and (2) can also be derived as Bellman equations from first principles.

Notice that with the strictest possible monitoring, i.e., $p=q=1$, the outside option when considering an offer is equal to a certain punishment, so then $\phi_{1}=$ $\rho R_{2}$. This implies that extreme monitoring does not necessarily entail the absence of punishments. With certain model parameter values, it may still be optimal for an individual to prefer a sanction and a forced future job offer acceptance over a current low offer. This is particularly likely if the offer under consideration is much lower than the average offer, and if the punishment $b_{2}-b_{1}$ is small.

It is also interesting to consider the expected present value $\widehat{R}_{1}$ and optimal reservation wage $\widehat{\phi}_{1}$ in the absence of a monitoring system,

$$
\rho \widehat{R}_{1}=b_{1}+\lambda \int_{\widehat{\phi}_{1}}^{\infty}\left(\frac{w}{\rho}-\widehat{R}_{1}\right) d F(w), \quad \text { with } \rho \widehat{R}_{1}=\widehat{\phi}_{1}
$$

By elaborating on equations (1) and (2) we obtain the following expression for $\phi_{1}$,

$$
\phi_{1}=p q b_{2}+(1-p q) b_{1}+\frac{\lambda}{\rho}\left[(1-p q) \int_{\phi}^{\infty}\left(w-\phi_{1}\right) d F(w)+p q \int_{0}^{\infty}\left(w-\phi_{1}\right) d F(w)\right]
$$

which has a similar structure as the reservation wage equation in a standard job search model. Clearly, the latter is obtained by imposing $p=q=0$. For general $p, q$, we obtain a weighted average of the reservation wage in a market without monitoring, and the present value flow after having been punished.

Using obvious notation, the transition rates from unemployment to employment before and after imposition of a sanction equal

$$
\theta_{u, 1}=\lambda\left(1-F\left(\phi_{1}\right)\right) \text { and } \theta_{u, 2}=\lambda
$$

For a system with given $p$ and $q$, the probability that a sanction occurs before a job exit is equal to $\lambda p q F\left(\phi_{1}\right) /\left(\lambda p q F\left(\phi_{1}\right)+\lambda\left(1-F\left(\phi_{1}\right)\right)\right)=p q F\left(\phi_{1}\right) /(1-(1-$ $\left.p q) F\left(\phi_{1}\right)\right)$. This can be seen by noting that a newly unemployed individual faces competing risks (a sanction and job exit) with constant rates $\lambda p q F\left(\phi_{1}\right)$ and $\theta_{u, 1}$, respectively. The proportionate effect of the sanction on the job exit rate equals 
$\theta_{u, 2} / \theta_{u, 1}=1 /\left(1-F\left(\phi_{1}\right)\right)$. This correspond to a parameter of the empirical model. The additive effect of a sanction on the mean accepted wage equals $\mathbb{E}_{F}(w)-$ $\mathbb{E}_{F}\left(w \mid w>\phi_{1}\right)$. The empirical model contains a parameter that captures the additive effect on the mean $\log$ accepted wage $\mathbb{E}_{F}(\log w)-\mathbb{E}_{F}\left(\log w \mid w>\phi_{1}\right)$. Of course the empirical parameters are not constrained to have a particular sign, and they may themselves depend on deeper determinants and characteristics of the individual and the labor market.

The additive effect on the job exit rate equals $\theta_{u, 2}-\theta_{u, 1}=\lambda F\left(\phi_{1}\right)$. Notice that this is bounded from above by $\lambda$.

\subsection{Theoretical predictions}

A number of insights follow from the model. Consider the general case where the model parameters are such that $\phi_{1}>\underline{w}$ : the reservation wage before a sanction is imposed exceeds the lowest possible wage offer in the market. This is a necessary condition to observe sanctions at all. It is clear that $\widehat{R}_{1}>R_{1}>R_{2}$, and consequently $\widehat{\phi}_{1}>\phi_{1}$. From the point of view of the individual, monitoring reduces the expected present value, and so does an actual punishment in a world with monitoring. By implication, $\theta_{u, 1}<\theta_{u, 2}$, and both are larger than the transition rate in a world without monitoring.

Consequently, monitoring affects the transition rate of all individuals (except for those who have a very low reservation wage $\widehat{\phi}_{1}$ anyway). This is the ex ante effect of the monitoring system, as opposed to the ex post effect due to imposition of a sanction.

Notice that if $\phi_{1} \leq \underline{w}$ then the individual probability of job acceptance is equal to one, so there will not be any sanctions. If the case worker is very lenient $(q=0)$ then the sanction rate is zero as well. Conversely, we have seen that in the strictest possible monitoring system $(p=q=1)$, an individual may still prefer to reject a low-wage offer in favor of a sanction. This reflects a first fundamental difference with monitoring schemes that target an endogenously chosen level of search effort by the individual (see Abbring, Van den Berg and Van Ours, 2005, for a theoretical analysis). In the latter scheme, perfect monitoring leads to absence of sanctions, even if the punitive benefits reduction is small. This is because perfect search effort monitoring is instantaneous and continuous in time and the effort constraint will be strictly enforced after a violation. Perfect monitoring of offers only takes place after offer rejections, and a rejection followed by a sanction may be worthwhile if it is followed by a high wage offer at a later point in time.

It is interesting to consider the ex post effect and the occurrence of sanctions 
for different subgroups of individuals. First, consider individuals for whom $F(\phi)$ is very small. Since $\phi_{1}:=(1-p q) \rho R_{1}+p q \rho R_{2}$, it follows that their expected present value of unemployment after rejection of an offer is low. At the same time, they are unlikely to reject an offer and therefore unlikely to get a sanction. These may be individuals with a low $R_{1}$ due to a low job offer arrival rate $\lambda$ and low benefits $b_{1}$. Their sanction effect is small as well. Notice that for moderate values of $F\left(\phi_{1}\right)$, the probability $p q F\left(\phi_{1}\right) /\left(1-(1-p q) F\left(\phi_{1}\right)\right)$ that a sanction occurs before a job exit can still be extremely small if $q$ is very small. In that case the sanction effect is not necessarily extremely small.

Secondly, consider the opposite case where $F(\phi)$ is large (i.e., close to one). This may capture long-term unemployed individuals who enjoy generous benefits $b_{1}$ whereas their skills have become obsolete and most offers that are made to them concern low-skill jobs with wages below $b_{1}$ (see Ljungqvist and Sargent, 1997, for an equilibrium analysis). Such individuals have a very high sanction rate and sanction effect. But now let us consider what happens if individuals can optimally choose their search effort $s$ as well. Let the job offer arrival rate now be specified as $\lambda s$, and let the search cost flow $c(s)$ be a convex increasing function of $s$ with $c(0)=c^{\prime}(0)=0$, so that the instantaneous income flow before a sanction equals $b_{1}-c(s)$. The optimal value of $s$ before a sanction follows from maximization of the right-hand side of the suitably adjusted equation (1), leading to

$$
c^{\prime}(s)=\max \left\{0, \frac{\lambda}{\rho} \int_{\phi}^{\infty}\left(w-\phi_{1}\right) d F(w)-\lambda p q\left(R_{1}-R_{2}\right)\right\}
$$

If $\phi_{1}$ is at the upper bound of the support of $F$, then the integral in the above expression vanishes, implying that $s=0$. The same result holds for values of $\phi_{1}$ close to the upper bound. If the monitoring regime is stringent then the last term on the right-hand side increases, so the reduction of optimal search effort is exacerbated. In sum, when these individuals can choose their level of search effort, then offer decision monitoring will be counteracted by a reduction of search effort. To put it bluntly, monitoring of offer decisions causes individuals with high benefits (or a high utility flow of being unemployed) to prevent that they will ever get an offer. The ex ante effect of monitoring is then perverse: more monitoring implies a lower job exit rate. We view this as a potentially important insight. Whereas job search effort monitoring always generates a positive ex ante effect, job offer decision monitoring does not.

We briefly mention two other differences between job search effort monitoring 
and job offer decision monitoring. These concern outcomes after the sanction. Recall that we assume perfect monitoring after the sanction. The first of the two differences concerns the magnitude of the ex post effect on the job exit rate. Suppose that search effort $s$ is endogenously determined. In the case of job offer decision monitoring, the job exit rate after a sanction equals $\theta_{u, 2}=\lambda s_{2}$, where $s_{2}$ is the optimal search effort after a sanction. Conversely, in the case of search effort monitoring, this rate equals $\lambda s^{*}\left(1-F\left(\phi_{2}\right)\right)$, where $\phi_{2}$ is the optimal reservation wage after a sanction and $s^{*}$ is the minimum required search effort as postulated by the UI agency. In the latter case, by choosing an appropriately high $s^{*}$, the job exit rate, and by implication the ex post sanction effect, can be pushed upwards to arbitrarily high values. In the former case this is not possible. Intuitively, the effect of job offer monitoring is bounded from above by the rate at which job offers arrive. (Of course, by pushing up $s *^{*}$ in search effort monitoring, the privately incurred search $\operatorname{costs} c(s)$ increase at an even higher speed. Also, if $s^{*}$ becomes very large then the distribution of the associated wage offers may change at the margin.)

The fourth and final difference between the monitoring regimes was already mentioned in the introduction of the paper, namely that the adverse effects of sanctions on post-unemployment outcomes may be smaller with search effort monitoring than with job offer decision monitoring. Perfect monitoring after a sanction implies full compliance after the sanction. With job offer decision monitoring, this means that compared to the situation before a sanction, punished individuals now also have to accept all offers of jobs with the lowest wages. With search effort monitoring, however, full compliance means that punished individuals have to search harder for any possible job. The latter includes both high-wage jobs and low-wage jobs.

All results in this section generalize to non-wage job characteristics. Basically, if the individual's utility flow function depends on the wage and on other characteristics then the role of the income flow variables in the present section is replaced by the corresponding utility flows.

We finish this section by briefly mentioning some implications of the above that are of importance for the specification of the empirical model. The empirical model is a reduced-form model in which hazard rates are allowed to vary over time and across observed and unobserved individual characteristics. The implications below also follow from models with monitoring of an endogenously determined search effort (see Abbring, Van den Berg and Van Ours, 2005). First, at the individual level, the transition rate from unemployment to employment makes a discrete upward jump upon imposition of a sanction. If individuals are 
homogeneous then the size of this jump, which is the causal effect of the sanction treatment, can be estimated from an unemployment duration model in which the moment at which a sanction occurs is a time-varying exogenous covariate.

Empirical analyses of duration data from a market with a given monitoring system do not allow for non-parametric identification of ex ante effects. So such analyses cannot be used to evaluate the effect of the monitoring system on unemployment durations. The latter objective requires at least some observed variation in the monitoring system itself.

Both the transition rate from unemployment to employment and the rate at which a sanction arrives depend on all the variables that the individual uses to determine his strategy. This is because both depend on $\phi_{1}$ (provided that $\left.\phi_{1}>\underline{w}\right)$. In reality, individuals are heterogeneous with respect to determinants of search behavior. Suppose that the individuals know their own value of some characteristic but that these values are not observed in the data. As we argued in Section 1, with punitive treatments, such a setting is plausible. Then both the transition rate from unemployment to employment and the rate at which a sanction is imposed depend on this unobserved characteristic. This creates a spurious relation between the duration until a sanction is imposed and the duration of unemployment. Note that a similar spurious relation is created if the policy parameters $p$ and $q$ of the sanction rate itself differ across individuals in a way that is not observed by the researcher.

\section{Data}

\subsection{Data registers}

Our main data are taken from a combination of two Swedish register data sets called Händel (from the official employment offices) and ASTAT (from the unemployment insurance fund). Händel covers all registered unemployed persons. ${ }^{5}$ It contains day-by-day information on the unemployment status, whether the unemployed is covered by UI, entries into and exits from active labor market programs and part-time unemployment, and the reason for the unemployment spell to end. As a rule, UI spells end in transitions into re-employment, education, social assistance, or other insurance schemes. Händel also includes a number of background characteristics, recorded at the beginning of the unemployment spell. ASTAT provides information on all benefits sanctions, including information on

\footnotetext{
${ }^{5}$ According to Carling, Holmlund and Vejsiu (2001), more than $90 \%$ of the individuals who are ILO-unemployed according to labor force surveys also register at the employment offices.
} 
the timing of the sanction, the main reason for the sanction, and the size of the benefit reduction.

Our observation window runs from January 1, 1999 until December 31, 2003. We only use information on individuals who become unemployed at least once within the observation window. An individual becomes unemployed at the first date at which he registers at the employment office as being "openly" unemployed. We ignore unemployment spells that are already in progress at the beginning of the observation window, because using them would force us to make assumptions about the period before the beginning of the window. We focus on re-employment durations, and consider any employment, full-time or parttime, which is retained for at least 10 days as employment. At later stages we separately model the decision to accept part-time employment. UI spells that terminate for other reasons than re-employment are considered being right-censored re-employment durations. We stop time while unemployed are enrolled into active labor market programs. Robustness analysis shows that our results are insensitive to this restriction. Apart from that, individuals are only followed up to December 2004. Ongoing spells at that date are right-censored. We restrict our analysis to everyone who was between 25-55 at the time of entry into unemployment and covered by UI. ${ }^{6}$ We only model the first sanction during an unemployment spell. Any effects of a second or third sanction are considered to be a part of the first sanction treatment effect. Finally, we exclude all unemployment spells for a specific individual that occur after a spell during which a sanction was given to that individual. This is because we exploit multiple spells to enhance the quality of the results, and we cannot rule out that a sanction also affects future subsequent spells.

The sanction and unemployment data are combined with survey data on wages and hours worked from Statistics Sweden's wage statistics. It provides us with information on actual wages per time unit, so these are not wages created from annual earnings and some measurement of hours worked. The wage is recorded as the monthly full-time equivalent wage. The survey is collected annually (during the fall) by Statistics Sweden in cooperation with employer organizations. It covers the whole public sector, all large private firms and a random sample of small firms (about 50 percent of all private sector employees). If we observe a wage within one year after the exit to employment we use this wage, otherwise the wage is considered to be missing. The information on hours worked is used

\footnotetext{
${ }^{6}$ We also exclude disabled individuals and everyone who some time during the research period participated in sheltered employment, because these are intended for unemployed with some kind of disability or handicap.
} 
to construct an indicator variable for full-time employment, defined as working 34 hours or more a week.

The wage data also include individual occupations. These are classified using SSYK 96 (Standard för svensk yrkesklassificering 1996), which follows the international standard ISCO-88. Each occupation is classified into 355 separate groups of occupations (four digits). The first digit classifies occupations by the general qualifications required to perform the tasks associated with each occupation. It divides the occupations into four levels: the occupations in group 1 normally require no or limited education, level 2 occupations require high school competence, level 3 occupations short university education, and the occupations at level 4 require longer university education (3-4 years or more). Additional digits capture the specialization skills associated with each occupation. We matched occupations to individual education levels taken from Statistics Sweden's database "Louise".

\subsection{Descriptive statistics}

Table 1 provides statistics on the unemployment spells and the duration until a sanction. In Subsection 5.4 below we explain that we choose to estimate models with an endogenously stratified sample. The current subsection provides information on the full data set and on the sample used for the model estimation. A large part, $65.7 \%$, of the re-employment spells in our analysis data set is not right-censored. Remember that the remaining $34.3 \%$ of the spells are ongoing at the end of the data period, or UI spells that are completed for other reasons than re-employment. During only $0.18 \%$ of the unemployment spells in our full sample a sanction is imposed, compared with $8.4 \%$ in the data set used for the model estimation. Relatively many sanctions, $46.7 \%$, are imposed during the first 100 days of unemployment. There is also a substantial number of sanctions, $16 \%$, imposed after 300 days or more in unemployment. Because of censoring, these raw figures underestimate the incidence of sanctions and the duration at which these are imposed. About $8 \%$ of the sanctions are given to second-time offenders and only about $0.5 \%$ to third-time offenders.

Table 2 provides statistics on the job-quality measures. For about $35 \%$ of the spells for which observe an exit to employment we observe the wage within one year after the exit. Not observing the wage can be due to fact that the individual is employed in small private firms or due to fact that the individual already left employment before the time of the survey. As the wage survey is conducted annually, the mean time from the exit to employment to the time of the wage 
survey is about half a year (179 days). Note that, because the survey is mainly conducted during the fall and because there is seasonal variation in exits from unemployment, the time from the exit to the survey is not uniformly distributed over 1-12 months. The mean monthly wage is about SEK 17,840 among the individuals for whom we observe the wage, and about $57 \%$ of these individuals have full-time employment. Furthermore, $57 \%$ find a job in the public sector, $31 \%$ in a large private firm, and $21 \%$ find a job in a small private firm. Here, a large firm is defined as having 200 employees or more.

The missing wage data may not be missing at random. First of all, remember that we observe the wage for all public sector employees, all employees at large private firms, and a random sample of those working in small firms. Suppose that individuals who are sanctioned accept lower wages on average. Small firms tend to pay lower wages than large firms, so there may be a selectivity in the wage observations, and this may lead to an under-estimation in absolute values of the negative effect of sanctions on wages. To explore this, we specify a logit model for the choice between accepting public sector or private sector employment, and, given the choice to enter the private sector, a logit model for the choice between accepting employment in a large firm or a small. In both models we control for a number of covariates, such as sex, age, level of education, time of inflow into unemployment, regional variables, level of education, the kind of profession the unemployed is searching for and whether the unemployed has education respectively previous experience in that occupation. We estimate these two logit models jointly using maximum likelihood, and the results are presented in Table 3. The results show no evidence of selection due to a sanction into small private firms. We therefore feel confident in assuming that it is random whether we observe the wage or not. The same holds for hours worked.

The second concern regards the fact that, in most cases, some time elapses between the exit from unemployment and the wage survey. It means that we do not observe the first wage after unemployment for individuals who have quickly moved into a second or even third employment. We neither observe the wage for those who have become unemployed or left the labor market entirely before the wage survey is conducted. Both these factors may bias our job quality estimates. If there is an effect of a sanction on the job security, relatively more individuals with sanctions will go back into unemployment before the time of the wage survey. As these individuals can be expected to be on the lower end of the wage distribution it will also bias our job quality estimates upwards. In addition, if unemployed with sanctions move relatively faster into a second employment, with a higher wage, it will also bias our job quality estimates upwards. To proceed ahead, even 
with these potential biases we find significant negative job quality effects.

\subsection{Around the date of the monitoring policy regime change}

In this subsection we provide descriptive statistics on the occurrence of sanctions shortly before and after the policy change of February 5, 2001. Ideally, a change in the monitoring regime offers an opportunity to investigate the ex ante threat effect.

As apparent from Figure 1, the reform did not lead to a substantial increase in the number of sanctions issued. Instead, apart from seasonal fluctuations, this number has been increasing slowly and steadily after the reform.

In addition, there are large regional differences in the development of the number of sanctions over time. Regional variation is to some extent due to the fact that only the individual case worker and the chief of the local PES office decide about whether a report should be sent to the unemployment insurance fund (recall the statements in IAF, 2006 mentioned in Subsection 2.2). Table 13 lists the mean number of sanctions per quarter by region. In Figure 2 and Figure 3 we display an index of the quarterly number of sanctions for each of the years 2000-2004 using the quarters of 1999 as base period. An index value of 2 in 2003 means that sanctions are twice as frequent in 2003 as in the same quarter in 1999. We display this for three regions in the southern and the central parts of Sweden, respectively. They reveal a wide regional variation in patterns after 2000 . We observe permanently increased sanction numbers in some regions, no change in some other regions, and temporary increases in sanctions in yet other regions. To focus more closely on the moment of the policy change, we list in Table 13 the ratio between sanction occurrences in the first quarter of 2001 and the first quarter of 2000, and the same for the other quarters in 2001 and 2000. These ratios are purged from seasonal variation. The statistics confirm the patterns in Figure 2 and Figure 3.

Clearly, from a methodological point of view, it is hard to reconcile the erratic and region-specific fluctuations in the occurrence of sanctions after the policy change to the idea of exploiting the discontinuity in the monitoring system for the estimation of ex ante effects. But at the very least we may conclude that the occurrence of sanctions has not increased substantially after the policy change. According to our theoretical model, there are two possible explanations for this. First, the case workers have decided to not to act on policy change but instead to continue not to recommend sanctions in case of violations, because they find a $25 \%$ benefits reduction still too severe. Obviously, in the new system, the punish- 
ments are less harsh than before, but from an international perspective they are still substantial. In the Netherlands, where sanctions are less severe, and monitoring is carried out by different individuals than the case workers, the individuals who carry out the monitoring state that they are less likely to issue a sanction if they feel that the unemployed individual faces adverse labor market conditions (see Van den Berg and Van der Klaauw, 2006). In agreement to this, studies with Dutch data find that individual characteristics that are associated with a low exit rate to work are also associated with a low sanction rate, confirming that the monitoring intensity depends positively on the individual's labor market conditions. In terms of our theoretical model, this first explanation would mean that the policy change does not lead to any changes in the parameters in the decision problem for the unemployed individual.

The second explanation for the low occurrence of sanctions after the policy change is that a more stringent monitoring scheme may motivate many individuals to avoid violations at all costs, i.e. that the policy change induced a strong ex ante effect. The net effect of an increase in the monitoring and a decrease in violations may then be that the occurrence of sanctions remains low. In terms of our theoretical model, the policy change is captured by an increase of $q$ which leads to a decrease of $\phi_{1}$ such that virtually all offers are accepted. In Subsection 3.2 we also showed that an increase of $q$ may lead to a reduction of search effort to zero, such that no offers are generated in the first place, and consequently sanctions do not occur. However, this is potentially only relevant for a subset of individuals whose benefits are high compared to the wages they may earn. Obviously, a zero effort gives rise to extremely long unemployment spells. (A third explanation is that monitoring was virtually perfect in both regimes, but this seems borne out by the motivation for the policy change as well as by the variation in enforcement across case workers.)

To distinguish between these explanations we have to examine the unemployment duration outcomes and the post-unemployment outcomes. The first explanation implies that the job exit rate $\theta_{u, 1}$ is the same in both regimes. The second explanation implies that this rate changes after the policy change. This is because in the first case $\phi_{1}$ does not change whereas in the second case it decreases. The identification of a subgroup of individuals with zero search effort in the new regime seems to be beyond what is empirically feasible, but we should keep in mind that such a subgroup may exist. We return to the issues of this subsection after having presented the duration model estimates in Section 6 . 


\section{$5 \quad$ Empirical model}

\subsection{Timing of Events model}

This section presents our empirical model. In Subsection 5.1, we present a basic bivariate duration model, for the duration until employment and the duration until the imposition of a sanction. This "timing of events" approach (Abbring and Van den Berg, 2003) is the standard approach in the literature on sanction effects. In Subsection 5.2 we extend this well known model into our full model, incorporating the job quality into the same model.

We normalize the point of time at which the individual enters unemployment to zero. We are interested in investigating how the duration $t_{s}$ until the imposition of a sanction affect the duration until employment, $t_{e}$. In order to illustrate the basic identification problem, suppose that we observe that the individuals who are sanctioned at $t_{s}$ have relatively short unemployment durations then this can be for two reasons: (1) the individual causal sanction effect is positive, or (2) these individuals have relatively favorable unobserved characteristics and would have found a job relatively fast anyway. The second relation is a spurious selection effect. To control for such spurious effects, we analyze both the distribution of $t_{e}$ for a given $t_{s}$ and the distribution of $t_{s}$ jointly. It is well known that these distributions can be conveniently represented by the corresponding hazard rates.

First, consider individuals who are unemployed for $t$ units of time. We assume that all individual differences in the re-employment rate at $t$ can be characterized by observed characteristics $x$, unobserved characteristics $V_{e}$, and a sanction effect if a sanction has been imposed before $t$. Next, consider the rate at which a sanction is imposed on an unemployed individual. Similarly as for the re-employment hazard, we assume that all individual differences in this rate can be characterized by observed characteristics $x$ and unobserved characteristics $V_{s}$. We further assume that the re-employment rate denoted by $\theta_{e}\left(t \mid x, V_{e}, t_{s}\right)$, and the sanction rate denoted by $\theta_{s}\left(t \mid x, V_{s}\right)$ both have the familiar Mixed Proportional Hazard $(\mathrm{MPH})$ specification, this gives

$$
\begin{aligned}
& \theta_{e}\left(t \mid x, V_{e}, t_{s}\right)=\lambda_{e}(t) \exp \left(x^{\prime} \beta_{e}\right) \exp \left(I\left(t>t_{s}\right) \delta\left(t \mid t_{s}, x\right)\right) V_{e} \\
& \theta_{s}\left(t \mid x, V_{s}\right)=\lambda_{s}(t) \exp \left(x^{\prime} \beta_{s}\right) V_{s}
\end{aligned}
$$

Here $I($.$) is an indicator function taking the value one if the argument is true$ and zero otherwise. $\delta\left(t \mid t_{s}, x\right)$ then represent the sanction effect, which we allow to vary both with observed characteristics and with time, $t-t_{s}$, since the imposition 
of a sanction. Further, $\lambda_{e}(t)$ and $\lambda_{s}(t)$ represents the duration dependence in the re-employment hazard and the sanction hazard, respectively.

Equations (5) and (6) give the joint distribution of $t_{e}, t_{s} \mid x, V_{e}, V_{s}$. Our data provide information on the distribution of $t_{e}, t_{s} \mid x$. Let $G$ denote the joint distribution of $V_{e}, V_{s} \mid x$ in the inflow into unemployment. It is clear that a specification of $G$, together with the specification of the joint distribution of $t_{e}, t_{s} \mid x, V_{e}, V_{s}$, fully determines the distribution of $t_{e}, t_{s} \mid x$, and thus the data. Abbring and Van den Berg (2003) show that all components of this model, including $\delta$, are identified, provided we make assumptions similar to those usually made in standard univariate MPH models with exogenous regressors. Identification is semi-parametric in the sense that given the MPH structure, it does not require any parametric assumptions on the components of the model. It allows for general dependence between $t_{e}$ and $t_{s}$ through both the causal effect of sanctions and related unobservables.

The identification does not require conditional independence assumptions or exclusion restrictions on the effects of $x$ on the individual hazard rates $\theta_{e}$ and $\theta_{s}$. This is important, since all variables that affect the sanction rate plausibly also affect the re-employment rate, and vice versa. Instead, identification is based on the timing of events, i.e. the timing of sanctions and of exits out of unemployment. Intuitively, what drives the identification of the sanction effect, $\delta$, is the extent to which the moments of a sanction and the moment of exit to employment are close in time. If a sanction is quickly followed by exit to employment, no matter how long the elapsed unemployment duration before the sanction, then this is evidence of a causal effect of a sanction. Any spurious selection effects through dependence between $V_{s}$ and $V_{e}$, gives a second relation between the two duration variables, but it can be shown that that relation does not give rise to the same type of quick succession of events. So the interaction between the moment of exit and the moment of a sanction in the conditional rate of events allows one to distinguish between the causal effect and selectivity. The Monte Carlo simulations in Gaure, Røed and Zhang (2007) support the use of this approach by showing that the estimates of the parameters of interest are robust with respect to functional form assumptions.

Formally, identification of the model relies on a number of implicit and explicit assumptions. We assume that a sanction does not affect the re-employment rate before the moment of the sanction, whereas the effects of the unobserved covariates are fixed during the spell. The former is often referred to as the noanticipation assumption. With sanctions, the moment at which an individual is caught is almost by definition unanticipated by the individual. As explained in 
Section 2 there are also several sources of unpredictability in the sanction process, which makes it even less likely that UI claimants anticipate the actual timing of the sanction. Next, since we specified the hazard rate it means that we implicitly assumed that there is a random component in the assignments that is independent of all other variables. Based on the randomness in the sanction process and the obvious randomness in the job-search process, we are confident that this assumption is satisfied.

Identification with single-spell data also requires that (i) $x$ on the one hand and $V_{u}, V_{s}$ on the other hand are independent in the inflow, and (ii) there is sufficient variation in $x$. However, since we often observe multiple UI spells for a given individual we can relax these two assumptions. We assume that multiple spells for one individual given the characteristics are statistically independent of each other, that the unobservables $V_{u}$ and $V_{s}$ are fixed across spells, and that the length of intervening spells between any two unemployment spells of a single individual are independent of $V_{u}$ and $V_{s}$. As shown by Abbring and Van den Berg (2003), under these assumptions, the assumptions (i) and (ii) can be discarded.

\subsection{Extension to post-unemployment outcomes}

We measure job quality by the monthly wage, and by whether the accepted job is full-time or part-time. These outcomes can be expected to depend on unobserved factors that are related to the unobserved determinants of the job exit rate and the sanction hazard. For instance, ability plays an important role for all these outcomes. In order to identify the effects of a sanction on the job quality we need to impose some structure. We assume that the causal effect and the selection effect only affect the mean log wage, and we assume that these effects are additive. Specifically, the wage at the start of the new employment can be expressed as

$$
\ln w=x^{\prime} \beta_{w}+\gamma_{w} I\left(t_{s}<t_{e}\right)+V_{w}+e_{w},
$$

where $\gamma_{w}$ is the sanction effect, $V_{w}$ unobserved individual characteristics, and $e_{w}$ is an error term which reflects random variation in the hourly wage. $e_{w}$ is assumed to be normally distributed with mean zero and variance $\sigma_{w}^{2}$. Similarly, we specify the decision to accept full-time employment as

$$
h=\mathbf{1}\left[x^{\prime} \beta_{h}+\gamma_{h} I\left(t_{s}<t_{e}\right)+V_{h}+e_{h}>0\right]
$$


where $h=1$ if the individual finds full-time employment. As before $\gamma_{h}$ is the sanction effect, $V_{h}$ unobserved individual characteristics, and $e_{h}$ an error term which reflects truly random variation. $e_{h}$ is assumed to have a standard logistic distribution.

We also acknowledge the tight link between the unobserved effects in the two job quality measures and the unobserved effects in the sanction hazard and the exit hazard. We take a simple linear form for this relation, as

$$
V_{w}=\beta_{w e} V_{e}+\beta_{w s} V_{s}
$$

and

$$
V_{u}=\beta_{h e} V_{e}+\beta_{h s} V_{s} .
$$

Here $\beta_{w e}, \beta_{w s}, \beta_{h e}$, and $\beta_{h s}$ captures the correlation between the unobservables in the model.

Abstracting from censoring, the joint density of $T_{e}, T_{s}, W, H \mid x$ at $T_{e}=t_{e}, T_{s}=$ $t_{s}, W=w, H=1$ is then

$$
\begin{aligned}
& \int_{0}^{\infty} \int_{0}^{\infty}\left(\lambda_{e}\left(t_{e}\right) \exp \left(x^{\prime} \beta_{e}\right) v_{e} \exp \left(I\left(t_{e}>t_{s}\right) \delta\left(t_{e} \mid t_{s}, x\right)\right)\right. \\
& \exp \left(-\exp \left(x^{\prime} \beta_{e}\right) v_{e}\left[\int_{0}^{\min \left(t_{e}, t_{s}\right)} \lambda_{e}(k) d k+I\left(t_{e}>t_{s}\right) \int_{t_{s}}^{t_{e}} \lambda_{e}(k) \delta\left(k \mid t_{s}, x\right) d k\right]\right) \\
& \lambda_{s}\left(t_{s}\right) \exp \left(x^{\prime} \beta_{s}\right) v_{s} \exp \left(-\exp \left(x^{\prime} \beta_{s}\right) v_{s} \int_{0}^{t_{s}} \lambda_{s}(k) d k\right) \times \\
& \frac{1}{\sigma \sqrt{2 \pi}} \exp \left(-\frac{\left(\ln w-x^{\prime} \beta_{w}-\gamma_{w} I\left(t_{e}>t_{s}\right)-\beta_{w e} v_{e}-\beta_{w s} v_{s}\right)^{2}}{2 \sigma^{2}}\right) \times \\
& \frac{\exp \left(x^{\prime} \beta_{h}+\gamma_{h} I\left(t_{e}>t_{s}\right)+\beta_{h e} v_{e}+\beta_{h s} v_{s}\right)}{1+\exp \left(x^{\prime} \beta_{h}+\gamma_{h} I\left(t_{e}>t_{s}\right)+\beta_{h e} v_{e}+\beta_{h s} v_{s}\right)} G\left(v_{e}, v_{s}\right)
\end{aligned}
$$

We jointly estimate this full model.

Consider identification of this full model. In short the duration part of the model identifies $G$, and given this we can estimate $\beta_{w e}, \beta_{w s}, \beta_{h e}$, and $\beta_{h s}$. We have then uncovered the selection process in the job quality decisions. It allows us to integrate out the unobserved effects in the wage equation and the hours worked equation. 


\subsection{Parameterizations}

Given the assumptions discussed above, including the MPH structure, the model is identified without any further parametric restrictions. However from a computational point of view we need to specify some parametric structure. We take flexible specifications of both the duration dependence functions and the bivariate unobserved heterogeneity distribution. We take both $\lambda_{e}(t)$ and $\lambda_{s}(t)$ to have a series representation

$$
\lambda_{i}(t)=\sum_{j=0,1, \ldots} \alpha_{i j} t^{j}
$$

Note that with a large number of polynomials any duration dependence pattern can be approximated closely. In the basic analysis we take polynomials of seventh order and lower for the exit hazard, and polynomials of third order and lower for the exit hazard. We have experimented with both more and less polynomials. The results are insensitive such changes, unless the number of polynomials are very few.

We use a bivariate discrete distribution with unrestricted mass point locations for $G$. This provides a very flexible specification as well as being computationally feasible. In our basic specification we take $V_{e}$ and $V_{s}$ to have two points of support each: $V^{1}, V^{2}$ and $V^{3}$ and $V^{4}$, respectively. The associated probabilities are denoted as follows:

$$
\begin{aligned}
& \operatorname{Pr}\left(V_{e}=V^{1}, V_{s}=V^{3}\right)=p_{1}, \quad \operatorname{Pr}\left(V_{e}=V^{2}, V_{s}=V^{3}\right)=p_{2} \\
& \operatorname{Pr}\left(V_{e}=V^{2}, V_{s}=V^{3}\right)=p_{3} \text { and } \operatorname{Pr}\left(V_{e}=V^{2}, V_{s}=V^{3}\right)=p_{4} \text {, }
\end{aligned}
$$

with $0 \leq p_{i} \leq 1$ for $i=1, . ., 4$, and $p_{4}=1-p_{1}-p_{2}-p_{3}$.

\subsection{Weighted exogenous sampling maximum likelihood estimation}

Our full data set contains over 1.6 million unemployment spells of about 827,000 individuals. In only about 3000 of these spells a sanction is imposed. To keep the empirical analysis manageable from a computational point of view and at the same time have enough spell with sanctions, we use weighted exogenous sampling maximum likelihood (WESML) estimation with an endogenously stratified sample. This method has not been used yet in the context of bivariate dependentduration models, and is not widely used in labor economics in general (see Ridder and Moffitt, 2007, for a detailed econometric overview). 
With exogenous sampling, a sequence of individuals is sampled and their outcomes and characteristics are recorded. In contrast, with endogenous sampling, a sequence of outcomes are sampled and the characteristics of the individuals with these outcomes are recorded. Endogenous stratified sampling has, for instance, been used in transportation economics (see e.g. Manski and Lerman, 1979, and Garrow and Koppelman, 2004) and in biostatistics. A key example is the study of rare diseases, for which it is reasonable to over-sample individuals with rare disease.

In our case we wish to use all information on the individuals who receive a sanction. We therefore sample all individuals who experience at least one sanction in the observation window, and take a smaller random sample $(14,000)$ of individuals who do not experience a sanction during this window. For these individuals, both sanctioned and non-sanctioned, we take all unemployment spells during the research period, leaving us with about 35,000 spells.

As shown by Manski and Lerman (1977), WESML provides a consistent estimator. Each observation is weighted with the ratio between the population fraction and the sample fraction of the strata it belongs to. Define $L_{i}$ as individual $i$ 's contribution to the likelihood function. Then, formally, WESML amounts to maximization of the weighted likelihood function

$$
\ln L_{w}=\sum_{i=1}^{N} \sum_{s=1}^{S} d(s) \frac{Q(s)}{H(s)} L_{i}
$$

where $d(s)$ is an indicator variable taking the value one if individual $i$ experience outcome $s, Q(s)$ the actual fraction of the population selecting alternative $s$, and $H(s)$ the probability that an individual selecting alternative $s$ is included in the sample. In our case, we have two alternatives: $s=1$ if the individual experiences a sanction during the research period, and $s=0$ otherwise.

Inference on precision also has to be adjusted. Manski and Lerman (1977) show that the appropriate covariance matrix is the familiar sandwich estimator $V=A^{-1} B A^{-1}$, with

$$
A=-\mathbb{E}\left[\left(\frac{\partial^{2} \ln L_{i}}{\partial \theta \partial \theta^{\prime}}\right)_{\theta=\theta^{*}}\right] \quad \text { and } \quad B=\mathbb{E}\left[\left(\frac{\partial \ln L_{i}}{\partial \theta}\right)_{\theta^{*}}\left(\frac{\partial \ln L_{i}}{\partial \theta^{\prime}}\right)_{\theta=\theta^{*}}\right] .
$$

The WESML estimates are not efficient. Efficient estimators based on endogenously stratified samples are developed in Imbens and Lancaster (1996). The basic idea is to use the populations moments as moment restrictions in order to improve 
efficiency. We decide not to pursue this approach. The reason for this is that our analysis sample will be large, and efficiency is not a crucial issue. Furthermore, in our case the most efficient estimator is to use the full sample of 1.6 million unemployment spells and estimate using standard ML.

\section{Results}

\subsection{Baseline results}

This subsection presents the baseline estimation results for the Timing of Events model, with a sanction effect that is constant over the population and over time. In the next subsection, we investigate the importance of temporal and crosssectional variation in $\delta$. From Subsection 6.3 and onwards we present the results from our full model, testing whether a sanction affects the quality of the accepted employment.

Table 4 presents the parameter estimates of the basic model. In this estimation we use the analysis sample presented in Section 4, and estimate the model using WESML. We use the individual characteristics listed in Table 2, and a set of inflow time dummies as observed covariates. As we will not normalize the scale of the unobservables, we have to exclude a constant from the regressors and one category from each set of dummies. ${ }^{7}$ We further normalize the two constants in the duration dependence, $\alpha_{s 0}=\alpha_{e 0}=1$.

The parameter of interest is the sanction effect $\delta$. The estimate of $\delta$ is positive and significant at the $1 \%$ level. The estimate indicates that a sanction increases the transition rate to employment with about $23 \%$. Compared to other studies on UI sanctions effects on the job exit rate this is a rather small effect. For the Netherlands, Abbring, Van den Berg and Van Ours (2005) find that a sanction doubles the job exit rate. For Switzerland, Lalive, Van Ours and Zweimüller (2005) estimate that the job exit rate increases with about $25 \%$ if a sanction warning is issued and with another $25 \%$ if a sanction is actually imposed. For Denmark, Svarer (2007) estimates increases of about $50 \%$ for men and a doubling for women. We can only speculate about the reasons behind these differences. Presumably, the institutional settings play a role. As described in Section 3.2, a system of job-offer decision monitoring, like the system in Sweden, places a natural upper bound on the sanction effect, because even if all offers are accepted,

\footnotetext{
${ }^{7}$ Our base category consists of women, with neither education nor experience in their occupation, who do not need guidance, living in the central parts of Sweden, with less than high school education and who started their unemployment spell in 1999.
} 
the job exit rate is bounded from above by the job offer arrival rate. A system where a minimum search effort is imposed after a sanction does not give rise to such an upper bound. Moreover, after a sanction, unemployed workers in Sweden may reduce their effort to zero in order to prevent further job offers and therefore additional punishments.

The signs of the regressor effects on both hazards are mostly as expected. Not surprisingly, we find selection on observables. For example, the dummy for individuals with university education generates a negative selection effect: highly educated unemployed have high re-employment rates and low sanction rates. Omitting this dummy as an explanatory variable would have resulted in underestimation of $\delta$ (if it is not captured by the unobservables). Further as expected, is the re-employment rate higher for highly educated, and for unemployed which have education in their profession. The effect of the observables on the sanction rate also reveals some interesting patterns. The gender dummy is insignificant, indicating that discrimination is not important for the sanction decision. We also note that the sanction effect is significantly lower among older workers.

Table 4 also reports the estimates for the baseline hazard as a set of coefficients for the polynomials of order one to seven. In order to provide more intuition behind these estimates we have produced two figures: Figure 4 and Figure 5, which display the estimated duration dependence at daily basis for the exit rate and sanction rate, respectively. Remember that the baseline hazard at time point zero is normalized to one. The exit rates to employment initially decrease, but after about 150 days of unemployment the exit rate starts to go down. For instance, after 600 days in unemployment the re-employment rate is about $30 \%$ lower compared with at the start of the unemployment period. Apparently, stigmatization and discouragement play a significant role for individual unemployment durations. The sanction rate gradually rises with time spent in unemployment. After about 300 days the maximum sanction rate is attained, and at longer durations there is a tendency towards decreased sanction rate. This is consistent with the fact that sanctions that are imposed because of some violation during the unemployment spell cannot be given at the start of that spell.

\subsection{Effect heterogeneity}

We now allow the sanction effect to vary over the population. We first specify $\delta$ as a function of explanatory variables $\mathbf{x}$, as follows: $\delta=x^{\prime} \gamma$, for some parameter vector $\gamma$ that replaces the single effect parameter $\delta$. Since our sample only contains a limited number of sanctions, we only include a small number of variables. 
We test for heterogeneous effects by sex, age, level of education, local unemployment rate, type of sanction regime and local sanction volume. Table 5 presents the estimated sanction effects. The other estimates are very similar as for the basic model, and are therefore not reported. We find interesting heterogeneous treatment effects: the sanction effect is significantly lower for males, and significantly lower for older unemployed. There is further no difference in the sanction effect by level of education, nor by local unemployment rate. We also included the regional occurrence of sanctions (number of sanctions divided by the number of unemployed), interacted with the treatment. If stigma is an important part of the sanction effect, the sanction effect should be lower in regions where sanctions are more common. However, we find no such differences.

Next, consider how the monitoring regime affects the sanction effect. As explained in Section 2 the Swedish sanction regime was changed in February, 2001. The reform introduced new, softer, sanctions, which reduced the size of the benefit reduction from $100 \%$ to $25 \%$. The new sanctions may influence the average sanction effect in two ways. First, the new sanctions are softer so that we expect the sanction effect to decrease for each individual. Second, the reform increased the sanction volume, implying that unemployed who commits less serious violations are also sanctioned after the reform. These individuals are most likely more sensitive to sanctions, which gives an upward tendency in the average sanction effect. The effect of the reform on the average sanction effect is therefore theoretically ambiguous. We find that the average sanction effect is significantly higher under the new sanction regime. We draw two conclusions from this result: (i) unemployed who commits less serious violations are more responsive to sanctions, and (ii) the new softer sanctions are also considered as a severe punishment.

It is also possible that sanctions have an effect only shortly after they have been imposed. To investigate this we introduce duration dependence in the effect parameter, as follows: $\exp (\delta)=\exp \left(\delta_{1}+\delta_{2}\left(t-t_{s}\right)\right)$. If $\delta_{2}$ is negative this means that the sanction effect decreases over time. Table 6 reports the estimates of $\delta_{1}$ and $\delta_{2}$. These results indicate very persistent effects of a sanction. We have multiplied the coefficient for $\delta_{2}$ with 100. It means that the average sanction effect on the re-employment hazard after 100 days is about $19 \%$, compared to $20 \%$ directly after the sanction has been imposed. There are several potential explanations to this persistent effect. It is reasonable to believe that individuals who have experienced a sanction are subject to intensified monitoring and attention from the case workers. In addition, second time offenders are punished harder, so that the persistent effect may be an effect of that the unemployed is eager to avoid future sanctions. 


\subsection{Job quality}

We now consider the effect of a sanction on characteristics of the subsequent employment. From a welfare point of view, as well from the point of view of the unemployed individual, any such effects are important. If the job accepted after a sanction is similar to the job accepted in the counterfactual situation of no sanction, then severe sanctions and intensive monitoring have less adverse effects than otherwise.

Table 7 presents the estimates of the full model. The parameters of interest are $\delta_{w}$ and $\delta_{h}$, the sanction effect on the wage and hours worked, respectively. Our estimates show a negative and significant (at 1\% level) sanction effect on both the wage and on hours worked. A sanction decreases the accepted wage with about $3.8 \%$. We measure hours worked using an indicator variable taking the value one for full-time employment and zero otherwise. Recalculated into marginal effects the results in Table 7 imply that a sanction increases the probability to accept part-time work with about 10.3 percentage points, or 15 percent. Part-time work is more often associated with a less secure employment, and of course, a lower income. We therefore interpret the effect on hours worked as a re-enforced negative effect on the job quality. It means that a sanction has a quite large negative impact on quality of the subsequent job.

The signs of the regressor effects on both the wage and hours worked are as expected. Males receive higher wages compared to women. Unemployed with high school education earn about $2 \%$ more than unemployed with less than high school education. The corresponding number for unemployed with university education is $11 \%$. We find similar patterns for hours worked. Males, highly educated, and unemployed in low employment areas, tend to find full-time employment to a higher degree. This confirms that wage and full-time employment both are perceived as attractive job characteristics.

\subsection{Long run effects}

It may be that the sanction effect on the accepted job is a short-term effect, and that those who suffer a sanction catch up quickly, say after two or three years. This would be in line with the results in Zijl, Van den Berg and Heyma (2009), who find that temporary jobs often serve as a stepping-stone into regular work. On the other hand it may also be the case that those who suffer a sanction end up on a lower job quality trajectory, with long-term or even permanent job quality effects. Obviously, if there are long run effect the negative welfare effects of sanctions are smaller. Investigating the long run effects is thus crucial from a 
policy perspective.

In order to investigate the long run effects of a sanction we re-estimate our full model using the wage and full-time status after two, three and four years instead of the wage and full-time status directly after the exit from unemployment. We use the same full model as specified in Subsection 5.2, including a normally distributed wage, a logit specification for the full-time part-time decision, and a flexible specification of the observed and unobserved effects in the model. Table 9 presents some descriptive statistics for these long run outcomes. Obviously, we cannot observe the wage for those who have left the labor market and not for those who once again are unemployed. As expected we therefore observe less and less wages as time passes on after the exit to employment. It means that we estimate these models with some reservations. However, as the wage several years after the exit from unemployment is rarely observed, we find this exercise meaningful.

Table 10 presents our long-term job quality estimation results. Here we only present the sanction effects, but remember that the models also include the duration until a sanction, as well as extensive controls for observed and unobserved heterogeneity. We find that sanctions have very persistent job quality effects. Our previous results indicated that a sanction decreases the wage directly after the exit from unemployment with 3.8 percent. Here, we find that this wage effect is 3.4, 4.3 and 4.7 after two, three and four years after the exit from unemployment, respectively. We find similar long run effects for hours worked: a sanction has negative and significant effect on the probability to get full-time employment. We conclude that those who get a sanction do not catch up quickly. From a welfare perspective this is an important result.

\subsection{Occupational changes}

One can separate out two main explanations for a long run effect. It could either be an effect of the unemployed; $(i)$ accepting a job with a lower occupational level, or (ii) accepting a less well paid job within the same occupation. From a policy perspective, separating between these two explanations is important. If a sanction forces individuals to switch into a less qualified occupation, it imply that these individuals are not able to utilize all their education and experience. It means that on average, acceptance of a job with a lower occupational level involves a larger loss of human capital than acceptance of a job in the same occupation. This loss becomes irreversible as human capital depreciates over time. It may therefore be more difficult for the individual to move out of a bad job match if 
the job has a lower occupational level. This makes it important to know whether sanctions often lead to a match in a lower occupational level.

We use two different approaches to test whether a sanction means that the unemployed accepts a job with a lower occupational level. In both approaches we utilize the occupation codes in our wage survey data. In the first approach we use the four official qualification levels. They are based on the "objective" qualifications required to perform each work, and not necessarily on the qualifications the individuals working in each occupation actually have. As described in Section 4, the different occupations are divided into four groups: occupations that require no or limited education, high school competence, short university education, and longer university education (3-4 years or more), respectively. It allows us to rank each occupation from one to four. In the second approach we use register data on the number of years of schooling on every individual in Sweden to classify the occupations. Using this education data and the entire wage survey for 2001, we calculate the mean number of years of schooling among the individuals employed in each occupation. It provides a measure of the qualification level of each occupation. We perform this classification at three different levels: dividing the occupations at one, two and three digit level, respectively.

In order to control for observed and unobserved effects we specify similar models as our regular full model. For the first approach we specify an ordered logit model for the four qualification levels. For the second approach specify a linear model for the mean number of years of schooling for each occupation, and assume that the error term is normally distributed. In order to control for selection on unobserved effect we allow for correlation between the unobservables in model. We take $V_{q}=\beta_{q e} V_{e}+\beta_{q s} V_{s}$, where $V_{q}$ is unobserved characteristics in the occupation classification measure, and $\beta_{q e}$ and $\beta_{q s}$ as for the regular full model measure the correlation between the unobservables in the model.

Table 11 provides descriptive statistics for the occupation data. We show information for the 8 groups at the one digit level. ${ }^{8}$ Column 1 and 2 show the proportion of unemployed entering into each occupation for our sample and the full sample, respectively. Column 3 reports the official qualification level obtained from SSYK for each group. These are the qualification levels used in the first approach. From these classifications it is clear that the occupations are primarily distinguished by the education normally required to perform the work associated with each occupation. Column 4 presents the mean number of years of schooling for the individuals employed in each group. Note that the difference between these

${ }^{8}$ We have excluded work in the armed forces and managerial work. The reason for this is that they are not classified into the four qualification levels in SSYK. 
groups is quite small. One reason for this is the existence of separate educational tracks.

Table 12 presents the estimation results: the upper panel displays the results from first approach and the lower panel from the second approach. For brevity, we only report the sanction effects. All models indicate a negative effect of a sanction on the qualification level. The effect is, however, not significant in the first approach model. Most likely, this is because these groups are very broadly defined. For the second approach, which utilizes the mean years of schooling to classify the occupations, we find significant effects. A sanction means that the unemployed tend to accept employment within occupations that on average require 0.036-0.047 less years of schooling. In other words, unemployed who experience a sanction on average switch into a slightly less qualified occupation, resulting in a loss of human capital. Because of the existence of separate educational tracks, this is likely to be a lower bound of the true loss.

\subsection{An assessment of the design of the monitoring policy}

In Subsection 4.3 we postulated two explanations for the fact that there was no persistent dramatic increase in the occurrence of sanctions after the monitoring policy change. It would be a formidable computational task to estimate a duration model with regime indicators, because the latter are time-varying over the course of a given spell of unemployment. Moreover, as we have seen, there is no uniform moment in time when observed outcomes jump to another level and remain stable afterwards. The occurrence of sanctions displays substantial region-specific fluctuations in the year after the policy change. For these reasons we do not estimate a before/after model. However, note that the calendar time indicators for the inflow moment do not display a significant difference when comparing 2000 to 2001. Because of this, the first-mentioned explanation is the most likely explanation: the policy change was ineffective due to the fact that case workers shun away from issuing sanctions more frequently. This interpretation is consistent with the facts that case workers have substantial discretionary power to implement policy guidelines, and that their primary task is to help the unemployed to find a job. In a way, their discretionary power is used to the maximum extent, through the rareness of punishment issuance.

As a result, across our observation window, the monitoring regime does not exert a strong ex ante or threat effect. This means that the ex post effects capture the causal effects of a sanction as compared to the outcomes in a labor market without monitoring (Abbring and Van den Berg, 2005). 
One could replace the current Swedish system by a system in which $(i)$ monitoring focuses on job search effort instead of job offer decisions, and (ii) monitoring is carried out by different individuals than the case worker who provides job search assistance. It is plausible that this would lead to a threat effect on the exit rate to work before punishment and as such would lead to a reduction of unemployment. This is both because with ( $i i)$ the moral dilemmas that the case workers currently face are avoided, and because with $(i)$ they cannot avoid sanctions by reducing their search effort to zero. Moreover, in such an alternative system one may expect less adverse effects of sanctions on post-unemployment labor market outcomes than in a system where $(i)$ is not satisfied, like in the current system. Our empirical results show strongly adverse effects on post-unemployment outcomes in the current system. Assuming perfect monitoring after a realized punishment, the system with monitoring of job offer decisions entails that punished individuals now have to accept the jobs they like least, whereas the other system entails that punished individuals have to search harder for any possible job. The jobs they like least are the jobs with a low job quality. If the effects on post-unemployment outcomes are adverse in a system with monitoring of offer decisions then they are also adverse in the other system, because in both systems, the sanction involves a negative income effect. However, the theoretical results imply that the size of these adverse effects is larger in the former system than in the latter.

\section{Conclusions}

We find that sanctions have adverse effects on post-unemployment outcomes. On average, they cause individuals to accept jobs with a lower hourly wage and less working hours per week. The estimated average reduction in the accepted wage is almost $4 \%$. The probability to move into full-time employment decreases with about $15 \%$. What is more, we provide evidence that post-unemployment outcomes are also affected in the long run. Sanctions causally increase the likelihood of the acceptance of a job at a lower occupational level. Such decisions are to some extent irreversible, in which case they involve a permanent human capital loss. From a present-value point of view, this means that sanctions entail a substantial welfare loss for at least some individuals.

Concerning the effects of sanctions on the transition rate into work, we find a significant positive effect. On average, this involves a $23 \%$ increase. Compared to estimates for the job exit rate in other studies, this is a rather small effect. At the same time, the Swedish UI sanction rate is much smaller than in most OECD 
countries.

We explain our findings by additional and novel empirical and theoretical analyses, and we combine the evidence in order to assess the current Swedish monitoring system. First, our empirical examination of the monitoring policy change in our observation window leads us to conclude that case workers use their substantial discretionary power to keep sanction rates low because they feel uncomfortable initiating punishments to their clients. This finding shows how difficult it is to implement monitoring policies if those who carry out the dayto-day monitoring have discretionary power and have personal contacts to the individuals to whom they are supposed to issue punishments. In our case, the findings implies that across our observation window, the monitoring regime does not exert a strong ex ante (or "threat") effect.

Secondly, our theoretical analysis derives implications of the fact that Swedish monitoring is primarily focused on the prevention of job offer rejections. Such a policy has particularly adverse effects on post-unemployment outcomes. Its emphasis on the acceptance of all job offers means that individuals are pushed to modify their behavior towards the acceptance of low-quality jobs. In addition, this policy induces some individuals to reduce their search effort to zero in order to prevent receiving any job offers at all. The ex ante effect of monitoring is then perverse for some individuals, with more monitoring implying a lower job exit rate. We view this as a potentially important insight. The theoretical analysis is also able to explain also explain why the ex post effect on the job exit rate is not very large. The system of job offer decision monitoring places a natural upper bound on the sanction effect, because even if all offers are accepted, the job exit rate is bounded from above by the job offer arrival rate. And, after a sanction, unemployed workers may reduce their effort to zero in order to prevent further job offers and therefore additional punishments.

We contrast the job offer decision monitoring system to the alternative and more common system of job search effort monitoring. The adverse effects of sanctions on post-unemployment outcomes may be smaller with search effort monitoring, because it pushes individuals to search harder for any possible job and not just the jobs with low quality. Moreover, search effort monitoring is not compatible with the perverse ex ante effect mentioned above, and the ex post effect on the job exit rate is not restricted by the kind of upper bound mentioned above.

All this suggests that it is worthwhile to consider an alternative system in which $(i)$ monitoring focuses on job search effort instead of job offer decisions, and $($ ii $)$ monitoring is carried out by different individuals than the case worker who provides job search assistance. Such a system may lead to a larger threat 
effect, a larger ex post effect on the job exit rate, and a smaller ex post effect on post-unemployment outcomes. Obviously, a larger threat effect could lead to lower unemployment durations for many individuals. It would be interesting to shed some more light on these issues by studying spatial and temporal variations in institutions and outcomes in more detail, but the currently low occurrence of sanctions precludes this avenue. We should also note that in very recent years the Swedish system has gradually adopted more features of search effort monitoring (OECD, 2007).

It is important to point out that a complete switch to such an alternative regime cannot be expected to completely rule out adverse effects on postunemployment outcomes. After all, if those effects are adverse in a system with monitoring of offer decisions then they will also be adverse in the other system, because in both systems, the sanction involves a negative income effect.

Our paper also makes a major methodological contribution to the estimation of causal effects of rare endogenous events on duration outcomes. We show that WESML with an endogenously stratified sample containing all treated is a useful estimation method if one has access to population-level register data. It allows for a computationally feasible analysis and provides estimates with high precision.

The finding that individuals move more often to a lower occupational level after a sanction may have implications for the more general issue of how steeply benefits should decline as a function of the elapsed unemployment duration. Theoretical studies of optimal UI design do not distinguish between jobs in the same occupation (with opportunities to mitigate the low starting wage through jobto-job transitions) and jobs with a lower occupational level (where long-run opportunities may be less abundant). Such a distinction may shed a new light on the optimal balance moral hazard with the likelihood that unemployed individuals are driven into sub-optimal job matches. We leave this as a topic for further research. 


\section{References}

Abbring, J.H. and G.J. van den Berg (2003), "The non-parametric identification of treatment effects in duration models", Econometrica, 71, 1491-1517.

Abbring, J.H. and G.J. van den Berg (2005), "Social experiments and instrumental variables with duration outcomes", Working paper, VU University Amsterdam, Amsterdam.

Abbring, J.H., G.J. van den Berg, and J.C. van Ours (2005), "The effect of unemployment insurance sanctions on the transition rate from unemployment to employment", Economic Journal, 115, 602-630.

Acemoglu, D. and R. Shimer (2000), "Productivity gains from unemployment insurance", European Economic Review, 44, 1195-1224.

Amemiya, T. and X. Yu (2006), "Endogenous sampling and matching method in duration models", Monetary and Economic Studies, 24.2, 1-32.

Bennmarker, H., K. Carling and B. Holmlund (2007), "Do benefit hikes damage job finding? Evidence from Swedish unemployment insurance reforms", Labour, 21, 85-120.

Carling, K., B. Holmlund, and A. Vejsiu (2001), "Do benefit cuts boost job findings? Swedish evidence from the 1990s", Economic Journal, 111, 766-790.

Garrow, L. and F. Koppelman (2004), "Predicting air travelers no-show and standby behavior using passenger and directional itinerary information", Journal of Air Transport Management, 10, 401-411.

Gaure, S., K. Røed and T. Zhang (2007), "Time and causality: A Monte Carlo assessment of the timing-of-events approach", Journal of Econometrics, 141, 1159-1195.

Government of Sweden (2000), Government Bill 1999/2000:139, En rättvisare och tydligare arbetslöshetsförsäkring, Ministry of Industry, Employment and Communication, Stockholm.

Gray, D. (2003), "National versus regional financing and management of unemployment and related benefits: The case of Canada", OECD Social Employment and Migration Working Papers", OECD, Paris.

Grubb, D. (2000), "Eligibility criteria for unemployment benefits", OECD Economic Studies, 32, 147-184.

Ham, J.C. and R.J. LaLonde (1996), "The effect of sample selection and initial conditions in duration models: Evidence from experimental data on training", 
Econometrica, 64, 175-205.

IAF (2006), Annual Report 2005, IAF, Stockholm.

IAF (2007), Kvartalsrapport 1 200\%:3, IAF, Stockholm.

Imbens, G.W. and T. Lancaster (1996), "Efficient estimation and stratified sampling", Journal of Econometrics, 74, 289-318.

Lalive, R., J.C. van Ours, and J. Zweimüller (2005), "The effect benefit sanctions on the duration of unemployment", Journal of the European Economic Association, 3, 1386-1417.

Ljungqvist, L. and T. Sargent (1997), "The European unemployment dilemma", Journal of Political Economy, 106, 514-550.

Manski, C.F. and S. Lerman (1977), "The estimation of choice probabilities from choice based samples", Econometrica, 45, 1977-1988.

Manski, C.F. and S. Lerman (1979), "Sample design for discrete choice analysis of travel behavior: The state of the art", Transportation Research, 13, 29-44.

OECD (2000), Employment Outlook 2000, OECD, Paris.

OECD (2007), Employment Outlook 200\%, OECD, Paris.

Olli Segendorf, Å. (2003), "Arbetsmarknadspolitiskt kalendarium II", Working paper, IFAU, Uppsala.

Ridder, G. (1986), "Life cycle patterns in labor market experience", Working paper, University of Amsterdam.

Ridder, G. and R. Moffitt (2007), "The econometrics of data combination", in J.J. Heckman and E. Leamer, editors, Handbook of Econometrics, Volume 6B, North Holland, Amsterdam.

Schneider, J. (2008), "The effect of unemployment benefit II sanctions on reservation wages", Working paper, IAB Nürnberg.

Svarer, M. (2007), "The effect of sanctions on the job finding rate: Evidence from Denmark", Working paper, IZA Bonn.

Van den Berg, G.J. and B. van der Klaauw (2005), "Job search monitoring and sanctions", CESifo Journal for Institutional Comparisons, 3.2, 26-29.

Van den Berg, G.J. and B. van der Klaauw (2006), "Counseling and monitoring of unemployed workers: Theory and evidence from a controlled social experiment", International Economic Review, 47, 895-936. 
Van den Berg, G.J., B. van der Klaauw and J.C. van Ours (2004), Punitive sanctions and the transition rate from welfare to work, Journal of Labor Economics $22,211-241$.

Zijl, M., G.J. van den Berg and A. Heyma (2009) "Stepping stones for the unemployed: The effect of temporary jobs on the duration until regular work", Journal of Population Economics, forthcoming. 


\section{Appendix}

Figure 1: Monthly number of sanctions 1999-2004.

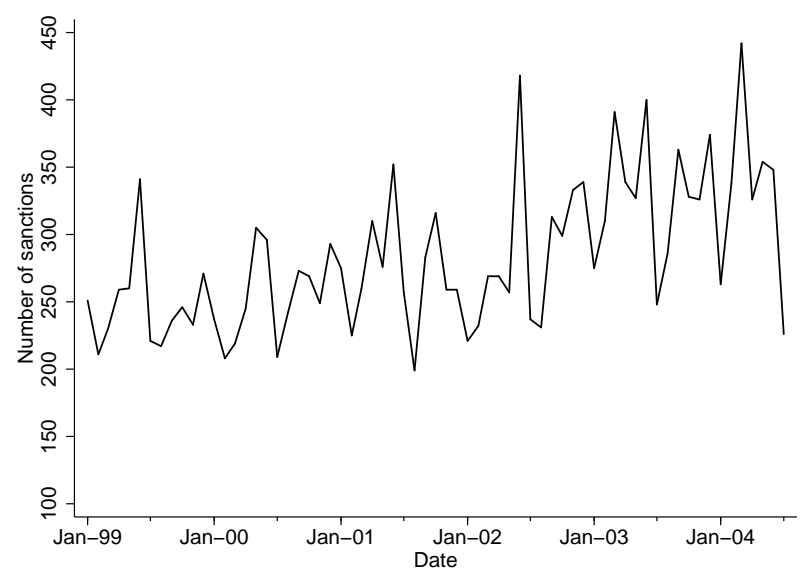

Figure 2: Index over quarterly number of sanctions 2000-2004 for three regions in southern Sweden. 1999 is base year.

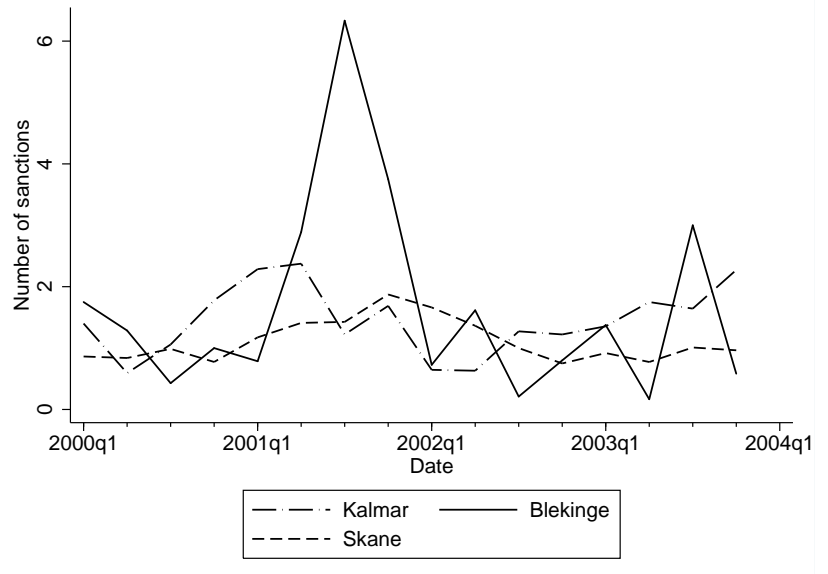


Figure 3: Index over quarterly number of sanctions 2000-2004 for three regions in the central parts of Sweden. 1999 is base year.

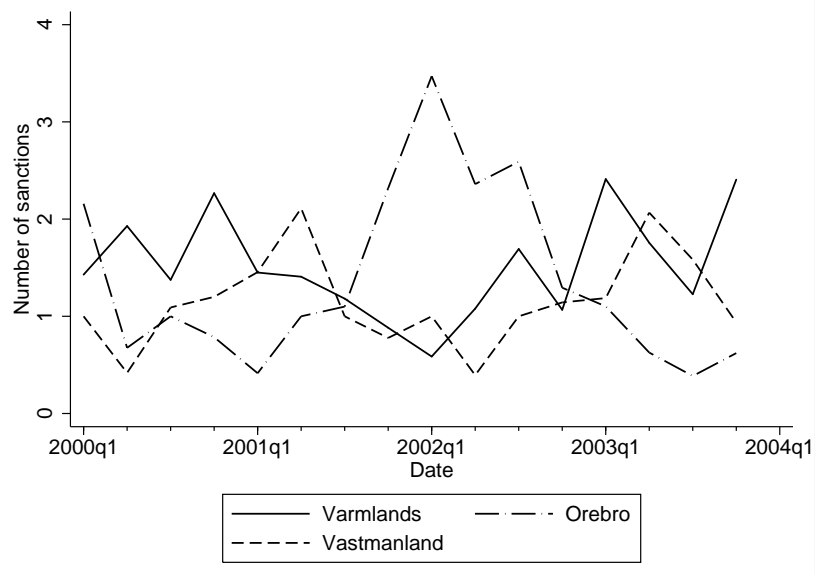

Figure 4: Estimated duration dependence. Normalized re-employment rate.

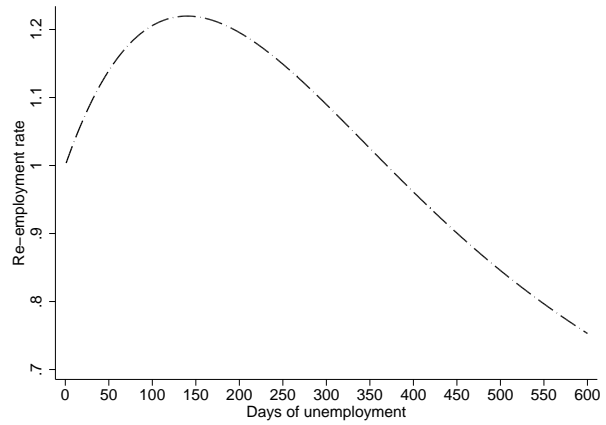

Figure 5: Estimated duration dependence. Normalized sanction rate.

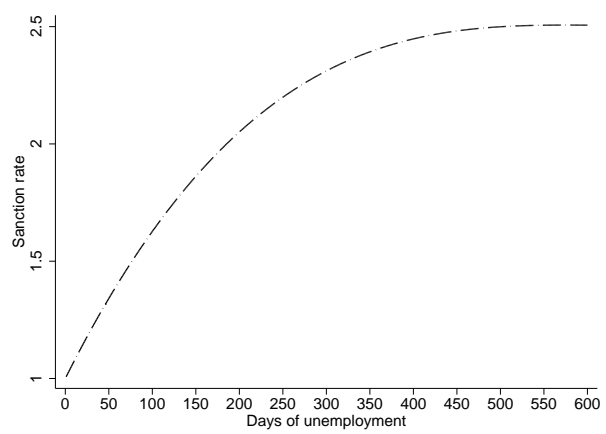


Table 1: Sample statistics for duration in unemployment and duration until a sanction

\begin{tabular}{|c|c|c|}
\hline & Full sample & Our sample \\
\hline \multicolumn{3}{|l|}{ Regardless of treatment } \\
\hline No. individuals & 827,074 & 16,941 \\
\hline No. spells & $1,665,420$ & 35,055 \\
\hline$\%$ with exactly one spell & 48.7 & 49.4 \\
\hline$\%$ with exactly two spells & 24.2 & 24.0 \\
\hline$\%$ with more than two spells & 7.1 & 7.0 \\
\hline$\% t_{s}$ observed & 0.18 & 8.4 \\
\hline$\% t_{e}$ observed & 65.7 & 65.2 \\
\hline average observed $t_{e}$ & $104.4(112.4)$ & $114.5(122.9)$ \\
\hline median observed $t_{e}$ & 68 & 74 \\
\hline \multicolumn{3}{|c|}{ Concerning spells with sanction observed } \\
\hline No. Spells & 2941 & 2941 \\
\hline$\% t_{e}$ observed & 56.1 & 56.1 \\
\hline average observed $t_{s}$ & $240.2(174.0)$ & $240.2(174.0)$ \\
\hline median observed $t_{s}$ & 193 & 193 \\
\hline average observed $t_{e}$ & $140.6(134.0)$ & $140.6(134.0)$ \\
\hline $\begin{array}{l}\text { median observed } t_{e} \\
\% t_{s} \text { in }\end{array}$ & 96 & 96 \\
\hline 0-50 days & 27.1 & 27.1 \\
\hline 50-100 days & 19.7 & 19.7 \\
\hline 100-150 days & 12.3 & 12.3 \\
\hline 150-200 days & 10.6 & 10.6 \\
\hline 200-250 days & 7.5 & 7.5 \\
\hline 250-300 days & 6.1 & 6.1 \\
\hline 300- days & 16.6 & 16.6 \\
\hline \multicolumn{3}{|l|}{ Type of sanctions } \\
\hline$\% 100 \%$ reduction for 60 days & 68.0 & 68.0 \\
\hline$\% 25 \%$ reduction in 40 days & 32.0 & 32.0 \\
\hline
\end{tabular}

Notes: The time unit is day. $t_{s}$ is time until sanction, and $t_{e}$ time in unemployment. Standard deviation in parenthesis. Full sample is the full sample of all unemployment spells, and our sample the selected sample described in the data section. 
Table 2: Sample statistics for wages and hours worked

\begin{tabular}{|c|c|c|}
\hline & Full sample & Our sample \\
\hline \multicolumn{3}{|l|}{ Wage data } \\
\hline$\%$ exit to employment observed & 65.7 & 65.2 \\
\hline \multicolumn{3}{|l|}{ Of which } \\
\hline Observe wage $\%$ & 36.5 & 35.1 \\
\hline Observe hours worked $\%$ & 30.4 & 29.2 \\
\hline Public sector employment \% & 55.9 & 57.2 \\
\hline Private sector firm $\geq 200$ workers & 31.2 & 30.4 \\
\hline Private sector firm $<200$ workers & 21.7 & 21.0 \\
\hline Monthly wage in SEK & $17941(4371)$ & $17843(4446)$ \\
\hline Full time ( $\geq 34$ hours a week) $\%$ & 58.7 & 57.0 \\
\hline Average time between exit and wage survey & $179.5(107.6)$ & $178.9(108.3)$ \\
\hline Median time between exit and wage survey & 161 & 161 \\
\hline \multicolumn{3}{|l|}{ Time between exit and wage survey } \\
\hline-60 days & 13.7 & 14.5 \\
\hline $61-120$ days & 22.3 & 21.8 \\
\hline 121-180 days & 18.7 & 19.0 \\
\hline 181-240 days & 13.7 & 13.4 \\
\hline 241-300 days & 14.6 & 14.0 \\
\hline 301- days & 17.0 & 17.4 \\
\hline \multicolumn{3}{|l|}{ Individual } \\
\hline Male $(\%)$ & 50.2 & 52.2 \\
\hline Education in occupation (\%) & 64.6 & 65.5 \\
\hline Experience in occupation (\%) & 39.6 & 39.7 \\
\hline Needs Guidance (\%) & 22.8 & 23.2 \\
\hline Age & $36.4(8.14)$ & $36.4(8.11)$ \\
\hline North (\%) & 22.1 & 22.3 \\
\hline Central $(\%)$ & 37.5 & 36.9 \\
\hline South $(\%)$ & 40.4 & 40.8 \\
\hline Less than high school (\%) & 20.3 & 21.3 \\
\hline High school education (\%) & 54.3 & 55.3 \\
\hline University education (\%) & 25.4 & 23.4 \\
\hline Local unemployment (\%) & $5.15(1.53)$ & $5.14(1.54)$ \\
\hline \multicolumn{3}{|l|}{ Time of inflow } \\
\hline 1999 & 21.9 & 21.9 \\
\hline 2000 & 20.0 & 20.4 \\
\hline 2001 & 19.0 & 19.6 \\
\hline 2002 & 19.4 & 19.6 \\
\hline 2003 & 19.7 & 18.5 \\
\hline
\end{tabular}

Notes: Wage is the first observed (within one year) after the exit from unemployment. Time of inflow is defined as the calendar year the unemployment spell starts. Full sample is the full sample of all unemployment spells, and our sample the selected sample described in the data section. Standard deviations in parentheses. 
Table 3: Logit estimates for the choice between private and public sector employment and the choice between large and small private firm

\begin{tabular}{|c|c|c|c|c|}
\hline & \multicolumn{2}{|c|}{ Public sector } & \multicolumn{2}{|c|}{ Large private firm } \\
\hline & Est. & S.e.. & Est. & S.e. \\
\hline Sanction effect & 0.038 & 0.107 & 0.067 & 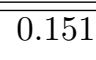 \\
\hline \multicolumn{5}{|l|}{ Individual } \\
\hline Male & -0.996 & 0.058 & 0.018 & 0.082 \\
\hline Education in occupation & 0.033 & 0.063 & 0.186 & 0.081 \\
\hline Experience in occupation & -0.030 & 0.063 & 0.193 & 0.086 \\
\hline Needs Guidance & 0.045 & 0.068 & -0.002 & 0.091 \\
\hline Log(age) & 0.739 & 0.126 & -0.417 & 0.167 \\
\hline North & 0.423 & 0.082 & -0.489 & 0.113 \\
\hline South & 0.040 & 0.062 & -0.178 & 0.083 \\
\hline High school Education & 0.270 & 0.078 & -0.314 & 0.096 \\
\hline University Education & 0.523 & 0.095 & -0.173 & 0.127 \\
\hline Local unemployment & 0.008 & 0.022 & 0.064 & 0.031 \\
\hline \multicolumn{5}{|l|}{ Inflow time } \\
\hline 2000 & -0.098 & 0.085 & -0.001 & 0.117 \\
\hline 2001 & -0.057 & 0.098 & 0.216 & 0.133 \\
\hline 2002 & 0.061 & 0.103 & 0.334 & 0.140 \\
\hline 2003 & -0.250 & 0.098 & 0.155 & 0.132 \\
\hline \multicolumn{5}{|l|}{ Searched profession } \\
\hline Administrative and managerial & -0.815 & 0.171 & -0.474 & 0.096 \\
\hline Sales & -0.476 & 0.158 & -1.600 & 0.093 \\
\hline Agricultural, forestry and fishing & -0.438 & 0.164 & -2.148 & 0.108 \\
\hline Technical and related & -1.426 & 0.212 & -2.110 & 0.165 \\
\hline Transport and communication & -0.741 & 0.186 & -2.028 & 0.135 \\
\hline Production & -0.295 & 0.149 & -2.517 & 0.096 \\
\hline Service & -0.530 & 0.170 & -1.165 & 0.099 \\
\hline Constant & -1.099 & 0.484 & 2.051 & 0.652 \\
\hline No. Observations & 8017 & & & \\
\hline Mean of outcome & 0.572 & & 0.583 & \\
\hline Log Likelihood & -11872 & & & \\
\hline
\end{tabular}

Notes: Public sector defined as an indicator variable taking the value one if the unemployed finds employment in the public sector. Large private firm defined as an indicator variable taking the value of if unemployed finds employment in a firm with more than 200 employees, given that the unemployed have found private sector employment. Sample consist of everyone in our analysis sample for which we observe exit to employment and have information on the type employment within one year after the exit. Estimated using WESML. 
Table 4: Estimates of basic model. Exit hazard and sanction hazard.

\begin{tabular}{|c|c|c|c|c|}
\hline & \multicolumn{2}{|c|}{ Exit Hazard } & \multicolumn{2}{|c|}{ Sanction Hazard } \\
\hline & Est. & S.e. & Est. & S.e. \\
\hline Sanction effect, $\delta$ & 0.205 & 0.035 & & \\
\hline \multicolumn{5}{|l|}{ Unobserved heterogeneity } \\
\hline$V^{1} / V^{3}$ & -4.646 & 0.151 & -5.630 & 5.003 \\
\hline$V^{2} / V^{4}$ & -3.362 & 0.153 & -5.860 & 1.268 \\
\hline $\operatorname{Pr}\left(v_{u}=V^{1}, v_{s}=V^{3}\right)$ & 0.005 & & & \\
\hline $\operatorname{Pr}\left(v_{u}=V^{1}, v_{s}=V^{4}\right)$ & 0.610 & & & \\
\hline $\operatorname{Pr}\left(v_{u}=V^{2}, v_{s}=V^{3}\right)$ & 0.248 & & & \\
\hline $\operatorname{Pr}\left(v_{u}=V^{2}, v_{s}=V^{4}\right)$ & 0.136 & & & \\
\hline \multicolumn{5}{|l|}{ Individual } \\
\hline Male & -0.084 & 0.017 & 0.075 & 0.039 \\
\hline Education in occupation & 0.231 & 0.018 & 0.069 & 0.041 \\
\hline Experience in occupation & 0.014 & 0.018 & -0.060 & 0.044 \\
\hline Needs Guidance & -0.006 & 0.019 & 0.011 & 0.049 \\
\hline Log Age & -0.373 & 0.039 & -0.405 & 0.088 \\
\hline North & 0.232 & 0.026 & -0.099 & 0.059 \\
\hline South & -0.007 & 0.019 & -0.191 & 0.043 \\
\hline High school Education & 0.123 & 0.021 & -0.131 & 0.047 \\
\hline University Education & 0.068 & 0.026 & -0.632 & 0.062 \\
\hline Local unemployment & -0.025 & 0.007 & -0.100 & 0.017 \\
\hline \multicolumn{5}{|l|}{ Inflow time } \\
\hline 2000 & 0.015 & 0.025 & 0.165 & 0.067 \\
\hline 2001 & -0.045 & 0.028 & 0.147 & 0.074 \\
\hline 2002 & -0.104 & 0.030 & 0.377 & 0.075 \\
\hline 2003 & -0.250 & 0.028 & 0.500 & 0.074 \\
\hline \multicolumn{5}{|l|}{ Duration dependence } \\
\hline$\alpha_{1}$ & $3.674 \cdot 10^{-3}$ & $0.915 \cdot 10^{-3}$ & $7.416 \cdot 10^{-3}$ & $1.505 \cdot 10^{-3}$ \\
\hline$\alpha_{2}$ & $-19.343 \cdot 10^{-6}$ & $10.010 \cdot 10^{-6}$ & $-12.124 \cdot 10^{-6}$ & $4.077 \cdot 10^{-6}$ \\
\hline$\alpha_{3}$ & $34.355 \cdot 10^{-9}$ & $46.081 \cdot 10^{-9}$ & $6.580 \cdot 10^{-9}$ & $3.106 \cdot 10^{-9}$ \\
\hline$\alpha_{4}$ & $-26.234 \cdot 10^{-12}$ & $103.956 \cdot 10^{-12}$ & & \\
\hline$\alpha_{5}$ & $4.345 \cdot 10^{-15}$ & $120.298 \cdot 10^{-15}$ & & \\
\hline$\alpha_{6}$ & $4.246 \cdot 10^{-18}$ & $68.365 \cdot 10^{-18}$ & & \\
\hline$\alpha_{7}$ & $-1.594 \cdot 10^{-21}$ & $15.098 \cdot 10^{-21}$ & & \\
\hline No. Individuals & 16,491 & & & \\
\hline No. Spells & 35,055 & & & \\
\hline Log Likelihood & $-175,709$ & & & \\
\hline
\end{tabular}

Notes: Sample is the selected sample described in the data section. Estimated using WESML with robust standard errors. The omitted category is: living in the central parts of Sweden with less than high school education. Local unemployment is the regional unemployment in percent at the time of inflow. 
Table 5: Estimates of heterogeneous sanction effect

\begin{tabular}{lcc}
\hline & \multicolumn{2}{c}{ Exit Hazard } \\
\hline \hline General & 0.292 & S.e. \\
Male & -0.202 & 0.142 \\
Log(age) & -0.306 & 0.057 \\
High school Education & -0.068 & 0.129 \\
University Education & 0.066 & 0.069 \\
Local unemployment & -0.017 & 0.085 \\
New system & 0.222 & 0.021 \\
Regional sanction occurrence & -0.033 & 0.070 \\
& & 0.107 \\
No. Individuals & 16,491 & \\
No. Spells & 35,055 & \\
Log-Likelihood & $-175,695$ & \\
\hline \hline
\end{tabular}

Notes: The model also includes controls for observed and unobserved variables. These estimates can be obtained from the authors upon request. Sample is the selected sample described in the data section. Estimated using WESML with robust standard errors. Local unemployment is the regional unemployment in percent at the time of inflow. Regional sanction occurrence is the ratio of the annual number of sanctions in the region and the annual mean stock of unemployed in the region, times 1000. Measured at the time of the sanction.

Table 6: Estimates of time-varying sanction effect

\begin{tabular}{|c|c|c|}
\hline & \multicolumn{2}{|c|}{ Exit Hazard } \\
\hline & Est. & S.e. \\
\hline General, $\delta_{1}$ & 0.204 & 0.043 \\
\hline$t-t_{s}, \delta_{2}$ & -0.031 & 0.026 \\
\hline No. Individuals & 16,491 & \\
\hline No. Spells & 35,055 & \\
\hline Log-Likelihood & $-175,695$ & \\
\hline
\end{tabular}

Notes: $\delta_{2}$ have been multiplied with 100 . The model also includes controls for observed and unobserved variables. These estimates can be obtained from the authors upon request. Sample is the selected sample described in the data section. Estimated using WESML with robust standard errors. 


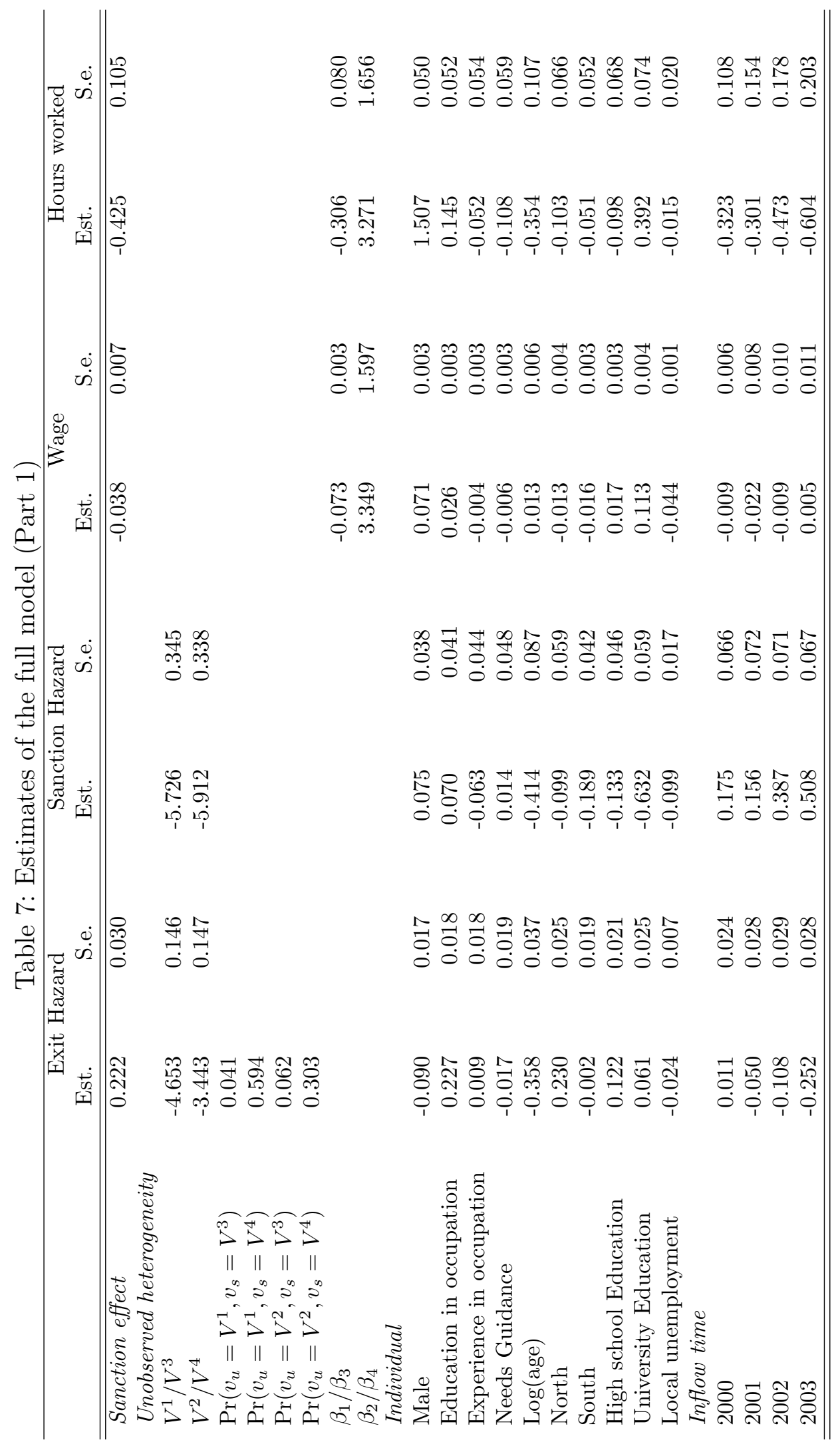




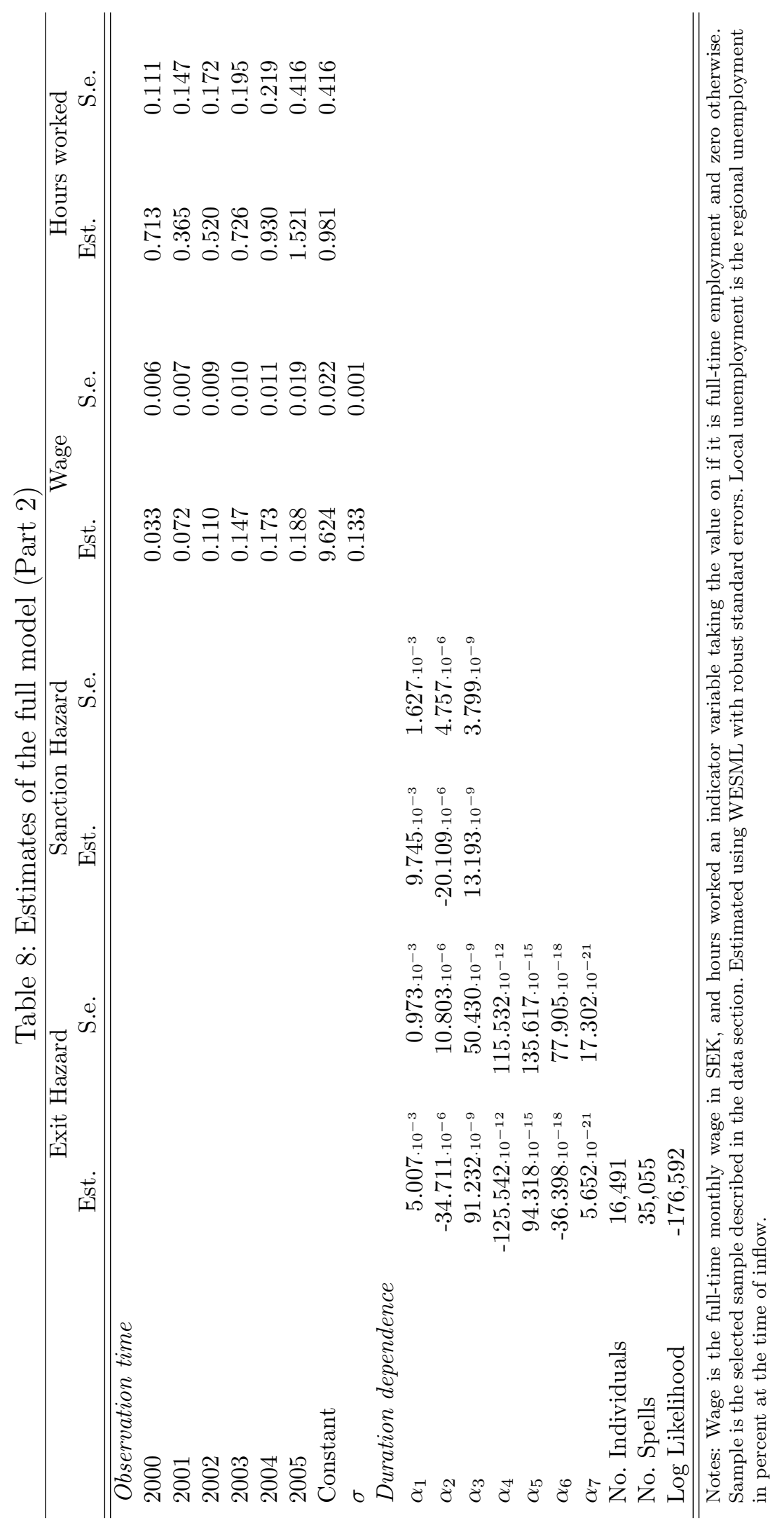


Table 9: Sample statistics for long-term wages and hours worked

\begin{tabular}{lcc}
\hline \hline & Full sample & Our sample \\
\hline Exit to employment observed & & \\
Of which & 65.7 & 65.2 \\
Observe wage after 1 year & 25.7 & 23.9 \\
Observe wage after 2 years & 21.3 & 19.8 \\
Observe wage after 3 years & 16.5 & 15.2 \\
& & $18952(4580)$ \\
Monthly wage in SEK after 1 years & $19001(4521)$ & $19545(4493)$ \\
Monthly wage in SEK after 2 years & $19616(4471)$ & $19942(4594)$ \\
Monthly wage in SEK after 3 years & $20054(4409)$ & 67.0 \\
Full time ( $\geq 34$ hours a week) after 1 year & 68.2 & 68.0 \\
Full time ( $\geq 34$ hours a week) after 2 years & 69.5 & 65.9 \\
Full time ( $\geq 34$ hours a week) after 3 years & 69.5 & \\
\hline
\end{tabular}

Notes: Wage after 1 year is the observed wage 1-2 years after the exit, and so on. Full sample is the full sample of all unemployment spells, and our sample the selected sample described in the data section. Standard deviation in parenthesis.

Table 10: Estimates of long-term job quality sanction effect

\begin{tabular}{lcccccc}
\hline & \multicolumn{2}{c}{ Exit Hazard } & \multicolumn{2}{c}{ Wage } & \multicolumn{2}{c}{ Hours worked } \\
& Est. & S.e. & Est. & S.e. & Est. & S.e. \\
\hline \hline One year after exit & 0.136 & 0.035 & -0.034 & 0.010 & -0.709 & 0.146 \\
Log-Likelihood & $-167,440$ & & & & & \\
& & & & & & \\
Two years after exit & 0.214 & 0.030 & -0.043 & 0.010 & -0.778 & 0.158 \\
Log-Likelihood & $-167,336$ & & & & & \\
Three years after exit & 0.208 & 0.034 & -0.047 & 0.017 & -0.530 & 0.197 \\
Log-Likelihood & $-176,429$ & & & & & \\
& & & & & & \\
\hline
\end{tabular}

Notes: Each panel (one, two and three years) represents different sets of results. Wage one year after exit is the full-time monthly wage in SEK, and hours worked an indicator variable taking the value on if it is full-time employment and zero otherwise, 1-2 years after the exit from unemployment, and so on. Each model also includes controls for observed and unobserved variables. The corresponding estimates are available upon request. Sample is the selected sample described in the data section. Estimated using WESML with robust standard errors. 
Table 11: Sample statistics for occupations.

\begin{tabular}{lcccc}
\hline \hline & $\begin{array}{c}\text { Fraction } \\
\text { full } \\
\text { sample }\end{array}$ & $\begin{array}{c}\text { Fraction } \\
\text { our } \\
\text { sample }\end{array}$ & $\begin{array}{c}\text { Qualification } \\
\text { level }\end{array}$ & $\begin{array}{c}\text { Years of } \\
\text { schooling }\end{array}$ \\
\hline Professionals & 16.9 & 16.0 & 4 & 14.4 \\
Technicians and associate professionals & 12.8 & 12.9 & 3 & 13.2 \\
Clerks & 8.5 & 8.5 & 2 & 11.7 \\
Service workers and shop sales workers & 31.9 & 33.2 & 2 & 11.3 \\
Skilled agricultural workers and fishery & 2.0 & 1.9 & 2 & 10.6 \\
Craft and related trade workers & 10.0 & 9.4 & 2 & 10.9 \\
Plant and machine operators & 9.7 & 10.2 & 2 & 11.0 \\
Elementary occupations & 8.3 & 7.9 & 1 & 10.5 \\
& & & & \\
Exit to employment observed \% & 65.7 & 65.2 & & \\
Of which observe occupation code $\%$ & 33.6 & 31.6 & & \\
\hline \hline
\end{tabular}

Notes: Full sample is the full sample of all unemployment spells, and our sample the selected sample described in the data section. The division of the occupations are based on Statistics Sweden's SSYK classification. Two categories armed forces and managerial occupations are excluded. The qualification level is based on the official classification, based on the qualifications required to perform the tasks associated with each occupation. Years of schooling is the mean years of schooling among all employed in the occupation group in 2001.

Table 12: Estimates of sanction effect on type of occupation.

\begin{tabular}{|c|c|c|c|c|}
\hline & \multicolumn{2}{|c|}{ Exit Hazard } & \multicolumn{2}{|c|}{ Occupation level. } \\
\hline & Est. & S.e. & Est. & S.e. \\
\hline \multicolumn{5}{|c|}{ Four level official classification } \\
\hline Sanction effect & 0.136 & 0.032 & -0.030 & 0.177 \\
\hline Log-Likelihood & $-182,041$ & & & \\
\hline \multicolumn{5}{|c|}{ Classification by years of schooling } \\
\hline Sanction effect one digit & 0.256 & 0.030 & -0.036 & 0.016 \\
\hline Log-Likelihood & $-183,391$ & & & \\
\hline Sanction effect two digits & 0.151 & 0.029 & -0.038 & 0.020 \\
\hline Log-Likelihood & $-175,157$ & & & \\
\hline Sanction effect three digits & 0.196 & 0.028 & -0.047 & 0.026 \\
\hline Log-Likelihood & $-182,041$ & & & \\
\hline
\end{tabular}

Notes: The four panels represents different sets of results. Four level official classifications is a ordered logit specification for the official SSYK classification of the occupations. Classification by years of schooling classifies the occupations by the mean years of schooling among all employed in that group of occupations, either at one, two and three digits level. Each model also includes controls for observed and unobserved variables. These estimates can be obtained from the authors upon request. Sample is the selected sample described in the data section. Estimated using WESML with robust standard errors. 
Table 13: Summary statistics for regional occurrence of sanctions.

\begin{tabular}{|c|c|c|c|c|c|}
\hline & \multirow[b]{2}{*}{$1000 N S / N U$} & \multicolumn{4}{|c|}{$N S 2001 / N S 2000$} \\
\hline & & Q1 & Q2 & Q3 & Q4 \\
\hline Stockholm & 1.46 & 1.12 & 1.32 & 1.18 & 1.19 \\
\hline Uppsala & 0.68 & 1.00 & 1.00 & 0.88 & 0.69 \\
\hline Södermanland & 0.99 & 5.60 & 0.95 & 0.72 & 0.21 \\
\hline Östergötland & 0.75 & 0.44 & 0.64 & 1.69 & 0.81 \\
\hline Jönköping & 1.10 & 1.21 & 1.35 & 1.74 & 0.70 \\
\hline Kronoberg & 1.12 & 1.83 & 1.90 & 0.63 & 0.67 \\
\hline Kalmar & 1.64 & 2.40 & 2.38 & 1.17 & 1.69 \\
\hline Blekinge & 0.79 & 0.79 & 2.89 & 6.33 & 3.75 \\
\hline Skåne & 1.12 & 1.14 & 1.38 & 1.39 & 1.81 \\
\hline Halland & 0.67 & 1.33 & 0.81 & 0.90 & 0.74 \\
\hline Västra Götaland & 0.82 & 0.95 & 0.86 & 0.75 & 0.96 \\
\hline Värmland & 1.21 & 1.45 & 1.41 & 1.14 & 0.76 \\
\hline Örebro & 1.35 & 0.41 & 1.04 & 1.05 & 2.23 \\
\hline Västmanland & 0.78 & 1.45 & 2.11 & 1.00 & 0.56 \\
\hline Dalarna & 0.72 & 0.73 & 1.33 & 0.52 & 1.13 \\
\hline Gävleborg & 0.69 & 0.57 & 0.69 & 1.05 & 0.72 \\
\hline Västernorrland & 0.89 & 1.33 & 1.75 & 1.13 & 1.56 \\
\hline Jämtland & 0.97 & 1.64 & 1.00 & 0.40 & 0.23 \\
\hline Västerbotten & 1.16 & 1.42 & 0.57 & 0.83 & 0.86 \\
\hline Norrbotten & 1.07 & 1.67 & 1.11 & 1.11 & 2.10 \\
\hline
\end{tabular}

Notes: $N S$ is the mean number of sanctions in the region, and $N U$ is the mean stock of full-time unemployed collecting unemployment insurance benefits in the region. $Q_{i}$ stands for the i'th quarter. 